\title{
LA PRODUCCIÓN DE LA MADRE-INDIA EN LA ESCUELA: reconceptualización del género y de los espacios públicos y privados
}

\author{
VÉRONIQUE BENEI \\ Laboratoire d’ Anthropologie Sociale des Institutions \\ et des Organisations Sociales, CNRS/Ecole des Hautes Etudes \\ en SCIENCes Sociales \\ Departamento de antropología, London School of Economics \\ v.benei@lse.ac.uk
}

\section{Resumen}

[ STE ARTí́CULO BUSCA REPLANTEAR LA DICOTOMÍA PÚBLICO/PRIVADO MEDIANTE LA [ reconsideración de la producción de género en los discursos y prácticas nacionalistas en los procesos de socialización en la escuela. Intenta demostrar que la producción social y cultural de las identidades regionales y nacionales en el contexto de la educación formal es fundamental en la constitución de la institución disciplinar de la escuela, para el modelado y disciplina del cuerpo y para la "normalización" de los sujetos, y co-sustancial en la producción del discurso y la corporalidad de género.

PALABRAS CLAVE: incorporación, sensorium, sentimientos de pertenencia, nacionalismo, India, género.

\section{Abstract}

T HIS ARTICLE SEEKS TO RECONCEPTUALISE THE PRIVATE/PUBLIC SPACE DICHOTOMY through a rethinking of gender production in nationalist discourses and practices and in particular through the socialisation processes largely occurring in the space of school. Here, I pursue the demonstration that cultural and social productions of regional and national identifications within the context of formal education are not only central to the making of the disciplinary institution of schooling, of modelled and disciplined bodies, and of "normalised" persons, but also co-substantial to the production of gender discursivity and corporeality.

KEY WORDS: Incorporation, sensorium, senses of belonging, nationalism, India, gender.

\author{
Revista Colombiana de Antropología \\ Volumen 42, enero-diciembre 2006, pp. 5597
}




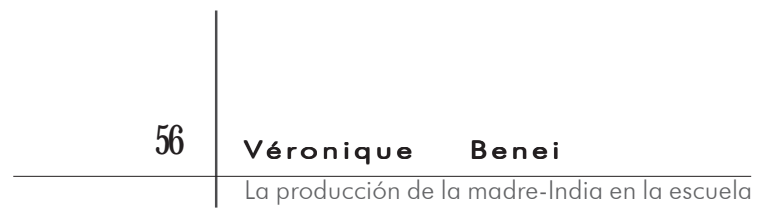

El mundo público y el privado están conectados inseparablemente; (...) las tiranías y servidumbres de uno son las tiranías y servidumbres del otro.

VIRGINIA WOLF

ACE CADA VEZ MÁS FRÍO EN KOLHAPUR, EN EL SUR DEL MAHARASHTRA, India del oeste, a pesar del ruido y la efervescencia en el estadio municipal en este día de la República, 26 de enero de 2000*1. El estadio está atestado de padres de familia. Como to-

* Traducción de Andrés Gordillo.

1 Maharashtra es el tercer estado más grande de India en términos de área, y el segundo en población: cerca de cien millones de habitantes. El estado, cuya capital es Mumbai, antes Bombay, queda en el centrooeste del país y es conocido como el más industrializado. La ciudad de Kolhapur, con cerca de $\mathbf{8 0 0}$ mil habitantes, cuenta también con muchas industrias -automotriz, mecánica y cuero, principalmente--, es la más grande del sur del Maharashtra y sede del distrito del mismo nombre. El Maharashtra y Kolhapur tienen un lugar especial en el imaginario de la nación india: la mayor parte de los habitantes del actual estado se definen en términos históricos y culturales como los herederos de la nación maratá -la casta maratá es todavía una de las más importantes y dominantes en Maharashtra-, constituida en el siglo diecisiete bajo la égida del jefe, que llegó a ser rey, Shivaji Maharaj, cuya historia ha sido objeto de muchas apropiaciones políticas en el curso del siglo veinte. La versión oficial de esta historia, que se ha seguido enseñando en las escuelas primarias después de la creación del estado regional (1960), es muy ambigua en su tratamiento de la cuestión religiosa. Tolerante con los musulmanes, Shivaji aparece como un hindú ferviente, y el manual escolar se presta a otras interpretaciones mucho más intransigentes en cuanto a los musulmanes. Es importante precisar que es contra la figura del musulmán que se ha construido el imaginario de la nación del Maharashtra, tal como la de la nación india. La división del país entre dos estados-naciones: Pakistán -un estado creado para los musulmanes que vivían en el sub-continente sur-asiático antes de la independencia-, e India-un estado secular en el que vive una gran mayoría de hindúes, es decir, más de 8\%\%-en 1947, opera todavía como una herida que no se ha podido curar. Este hecho se conceptualiza también como la amputación y la violación del cuerpo de la nación como madre-India. Además, Kolhapur tiene un vínculo especial con la historia de Shivaii, ya que reivindica una herencia directa con el fundador de la nación maratá. Como en el resto del estado, la gran mayoría de la gente en Kolhapur es de religión hindú; acá también, la minoría religiosa más importante en términos demográficos y políticos son los musulmanes, que representan $\%$ de la población local.

2. Cada estado tiene autonomía relativa en varios asuntos, incluida la educación. Los programas se deben ajustar a las recomendaciones hechas por la oficina central-nacional-, dos los años, han venido a presenciar las presentaciones de sus hijas e hijos en las justas de las escuelas primarias, organizadas por la corporación municipal ${ }^{2}$. Sin importar sus diferencias de estatus en la jerarquía local, están congregadas la mayoría de las escuelas de la ciudad: públicas, privadas, semiprivadas, elitistas, tradicionales, progresistas $\mathrm{y}$ de la derecha hindú. Todas están reunidas para la conmemoración patriótica anual. A medida que el espectáculo avanza, algunos profesores se ocupan de las últimas correcciones y ensayos, aplican los últimos toques de maquillaje en las mejillas de los participantes y les hacen las últimas recomenda- 


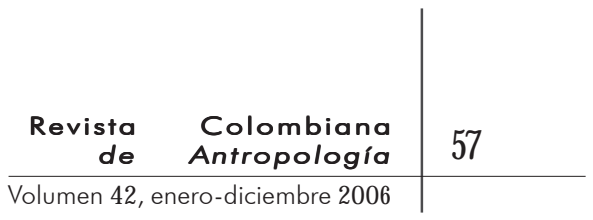

ciones. Cada escuela, según su turno, presenta sus

- pero los elabora la oficina regional de cada estado, y por eso pueden variar según especificidades locales. En Maharashtra, aun cuando la lengua oficial sea el maratí, como lengua de instrucción escolar se autorizan otros cinco idiomas, incluso el inglés. No obstante, la mayoría de las escuelas primarias funcionan en maratí, incluso en Kolhapur, donde cerca de $85 \%$ de los niños estudiaba en maratí durante la época de mis investigaciones. presentación, la música termina, los actores hacen la reverencia, el público aplaude. Cuando el escenario se desocupa otra escuela se prepara para entrar, entre susurros de silencio. Como muchas otras, inicia su presentación con una canción de bienvenida (swagatam), seguida por la danza del pescador (kohli natak). Igual que muchos otros, los actores representan en sus actos la graciosa presencia de Bharat Mata, a menudo mientras suena Mere watan ke logon: canción interpretada a lo largo de India durante las ocasiones patrióticas, fue popularizada por Lata Mangeshkar, una de las cantantes más famosas del país, originaria también de esta parte del Maharashtra. Se dice que en su primer recital su interpretación conmovió a Jawaharlal Nehru, el primer ministro de la nación independiente, al punto de llenarle de lágrimas. Cuando la música comienza, una joven hace su entrada majestuosa por la derecha de la escena, vestida con un sari rosa bordado de oro. Luce joven, grave y hermosa. De ambos lados de su diadema dorada cuelgan dos largas trenzas de cabello negro. La audiencia enmudece mientras la mira con atención deslizarse por la plataforma. Lleva la bandera tricolor de la India en su mano derecha, mientras en la izquierda sostiene un cetro tridente (trishur). En el mismo momento, en la parte posterior del escenario aparece un mapa de la India, en poliestireno. La diosa madre nacional, encarnada ahora, se ha detenido en el centro del escenario, mientras se alejan las últimas notas de la canción patriótica. Su figura sobrepuesta al mapa es una amalgama perfecta de territorio nacional, divinidad, feminidad e hinduismo. Los rostros de muchos hombres y mujeres de la multitud tienen su mirada transportada: ojos brillantes, atención intensa, sonrisas amplias, sus caras se balancean en señal de aprobación; los gestos corporales de gran parte de la audiencia local que contempla a su hija en el escenario sugieren un acto de (re)conexión con un ideal imaginado de nación.

Suspendida lejos de la vida cotidiana, en esos instantes la joven estudiante ha dejado de ser una muchacha (en inglés: "maiden") cualquiera de Kolhapur. Tampoco se puede afirmar 


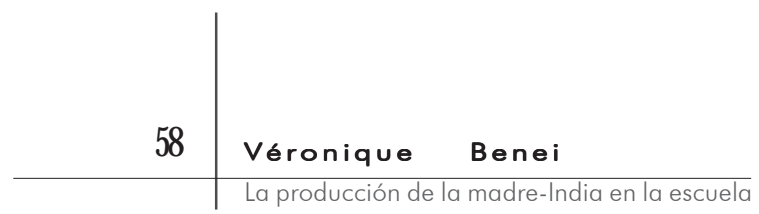

que sea apenas una personificación de Bharat Mata: ella es ahora la madre India. Es la misma deidad nacional encarnada, como la muchacha (ditto) anónima convertida de repente en obsesivo objeto de culto en Devi (La diosa), película dirigida por Satyajit Ray. La comparación, sin embargo, termina en este punto. Mañana, Bharat Mata regresará a su vida cotidiana en la escuela, portando el uniforme diario como sus demás compañeras. Pero, de múltiples maneras, su actuación no está absolutamente desconectada de la vida diaria, pues la recreación de la madre India hace parte integral de la rutina diaria de las escuelas maratíes. En ellas, la liturgia matutina que empieza el día escolar consiste en la re-creación cotidiana de la deidad nacional mediante oraciones, canciones y producciones, discursivas y físicas. Por lo mismo, la encarnación anual de Bharat Mata representa más que un momento aislado en el calendario escolar: es la culminación de imaginaciones y anhelos nacionales, la cristalización de esperanzas y sueños, una condensación tangible de la creación de la "madrediosa-nación” India. ¿Cuáles son las modalidades de esa producción fuera de esos momentos litúrgicos? ¿Qué les da tanta fuerza y sentido en la economía emocional y simbólica de tantos maharashtrianos? ¿Cómo sigue reproduciéndose a diario y contribuyendo a la producción de género en la familia, la escuela y la nación? Por último: ¿qué sugiere este ejemplo en cuanto a una supuesta dicotomía público/privado?

$* * *$

Este artículo busca replantear la dicotomía público/privado mediante la reconsideración de la producción de género en los discursos y prácticas nacionalistas. Mucho se ha dicho acerca de la posmodernidad y el "descentramiento del yo". En la reubicación de la interioridad del sujeto ha sido crucial una crítica legítima a la idea ilustrada de un yo consistente, unificado, que operaría en una racional "esfera pública burguesa" habermasiana. Frente a esto, la perspectiva posmoderna ha hecho énfasis en la noción de un yo fragmentado, así como en la pluralidad de voces discordantes y conflictivas que emergen una vez levantado el velo ilusorio de racionalidad consensual (Lyotard, 1984). Tal vez la sentencia de muerte de metanarrativas como la "esfera pública, burguesa racional”, y su, a menudo, corolario naciona- 


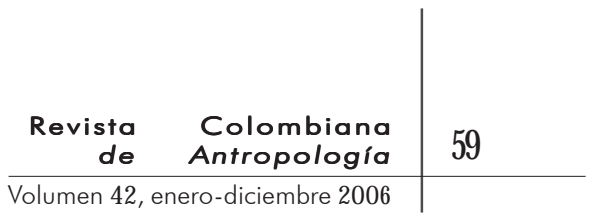

lismo, haya sido excesivamente optimista. Sin embargo, la crítica propuesta por algunos de los pensadores del posmodernismo no carecía de potencial heurístico (Lyotard, 1982). Su potencial radicaba en el reconocimiento de que las sociedades modernas, también ellas, descansan en "grandes narrativas", y que incluso el proyecto de la Ilustración discutido por Habermas es otra tentativa más de una explicación autoritaria, que incita, ella misma, a su deconstrucción. De hecho, tal deconstrucción fue hecha en una importante obra colectiva en la que se señalaban los sesgos sexistas, idealistas y de determinación de clase del planteamiento de Habermas (Calhoun, 1997). La mayor parte de esta crítica, si no toda, se expresó en términos de cualificar y redefinir la esfera pública, términos que han seguido operando sin distanciarse del conjunto de las oposiciones derivadas que han organizado la comprensión epistemológica moderna euroamericana de lo sexual desde comienzos del siglo veinte (Sedgwick, 1990, citada por Epstein y Johnson, 1998) ${ }^{3}$.

Un comentario semejante es válido también con respecto a los estudios subalternos y poscoloniales. Porque parece haber una paradoja en la forma en que los estudios poscoloniales y subalternos adoptan la deconstrucción posmoderna. La empresa intelectual de los estudios subalternos se ha

3 En particular, este repertorio de categorías, como lo ha sostenido la teoría feminista, estaba organizado alrededor de la division hetero-/ homo-, que incluía: público/privado, masculino/femenino, secreto/abierto, ignorancia/conocimiento e inocencia/iniciación (Sedgwick, 1990, citada por Epstein y Johnson, 1998: 92). una pluralidad de voces, lo que la destaca de otras. La reinscripción de las masas "desprovistas de voz" -y, además, la reinstauración paralela de sus sentidos de poder- en narrativas históricas de la nación, ha estado acompañada por la necesidad sentida de radicalizar la crítica a la Ilustración. Pero la paradoja radica en que mientras los estudios subalternos han clamado por la necesidad de descentrar la metanarrativa colonial del capitalismo y el cuerpo de conocimientos que esta ha constituido, no han llegado a cuestionar las "categorías ordenadoras y omniscientes” (Arfuch, 2002: 18-19) que prevalecen en el paradigma ilustrado. De hecho, los estudiosos de lo subalterno han continuado trabajando ampliamente con las mismas categorías que contribuyeron a la construcción de un discurso racional burgués en congruencia con la emergencia de los nacionalismos. Por ello, las nociones totalizadoras de la esfera "pública” y "privada” han permanecido sin discutir en muchos 


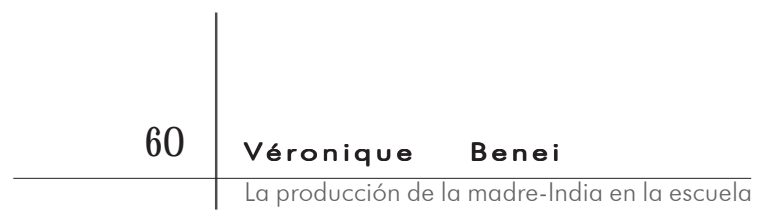

debates en los estudios surasiáticos y, más generalmente, en los poscoloniales.

Partha Chatterjee (1993), en un trabajo que en la actualidad es una obra de referencia sobre el nacionalismo indio ${ }^{4}$, ha profundizado en la formación conjunta de géneros y espacios. Como es bien sabido, su argumento se desarrolla de la siguiente manera:

\begin{abstract}
El nacionalismo anticolonial crea dentro de la sociedad colonial su propio ámbito de soberanía [...] por medio de la división del mundo de las instituciones sociales y de las prácticas en dos ámbitos, el material y el espiritual. El material es el ámbito del "afuera": de la economía y de la burocracia, de la ciencia y la tecnología, un ámbito en el que Occidente ha probado su superioridad y Oriente ha fracasado [...] El espiritual, por otra parte, es un ámbito "interno" que lleva las marcas "esenciales” de la identidad cultural (1993 6).
\end{abstract}

En otras palabras, el colonialismo británico en Bengala no habría sobrepasado el umbral de un "ámbito interno de la cultura nacional India”, una de cuyas áreas era la familia, parte constitu-

4. Aun cuando en Colombia se identifica a los ciudadanos indios como hindúes, estos últimos son quienes profesan el hinduismo. Luego veremos que la cuestión se complica un poco más con la utilización política del hinduismo o, mejor dicho, de una version del hinduismo, por varios movimientos y partidos políticos "de extrema-derecha hindú". tiva principal de la esfera privada, en cuyo seno se esperaba que los indios estarían en capacidad de desarrollar una "indianidad moderna”, construyéndola como una "forma esencialmente diferente" de su equivalente europeo. A la manera de una esfera pública, desarrollada con la ayuda de la prensa y de otros medios, una esfera privada, planteada como el "adentro" y cuyo epítome era el "hogar” (ghar), se produjo y consideró autónoma frente al estado colonial. La así considerada esfera privada estaba habitada principalmente por mujeres. Se esperaba que ellas atendieran la (re)producción social mientras aseguraban la transmisión de unos (recién redefinidos) valores morales (todavía) patriarcales. Entre tanto, los hombres "afuera" (baher), en el mundo real, estaban ocupados en la constitución de la "esfera pública". Y debido a que la esfera privada era en realidad el único campo sobre el cual, fuera del colonialismo castrador, podían ejercer autonomía y afirmar una detentación sin contestación, los hombres definieron y reconfiguraron la esfera privada a partir de debates sostenidos en la esfera pública. Lo anterior nos alerta, sobre todo, acerca de las 


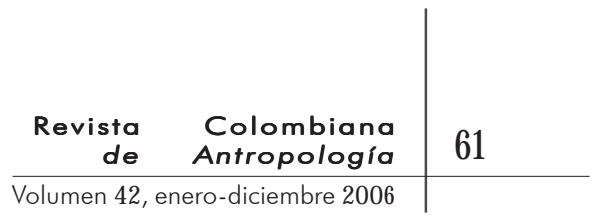

intrincadas relaciones entre los espacios definidos arbitrariamente como "público" y "privado". Del mismo modo que lo han hecho, por cierto, los trabajos que analizan los debates de los siglos diecinueve y veinte en torno a las condiciones sociales de las mujeres -sobre las segundas nupcias en la viudez, la práctica de la dote, la edad de matrimonio y otros asuntos- en las que implícitamente resultan ensombrecidas las líneas divisorias de una estricta dicotomía público/privado y donde se demuestra, como lo hizo Tanika Sarkar (2002) para el norte de la India, que las mujeres desempeñaron un papel importante como actores sociales activos, tanto en la "esfera privada" como en la construcción "pública” de una identidad e imaginario nacional indio (hindú) -que, a pesar de una constitución secular está largamente elaborado en términos simbólicos hindúes- ${ }^{5}$. Sin embargo, sólo desde hace poco se empezó a cuestionar de manera explícita la inadecuación de las nociones respectivas de esfera "pública" y "privada". Sudipta Kaviraj (2001), en particular, subraya su nebulosidad y sus solapamientos momentáneos. Aun así, es necesario

5 Para una revisión previa muy ilustrativa al respecto véanse también Radha Kumar (1993, especialmente capítulo 3, "Towards becoming 'The mothers of the nation": 32-52), y Charu Gupta (2001), quien hizo un recuento detallado de la generización y comunalización de los espacios y sus efectos polarizantes en las comunidades hindúes y musulmanas. dar cuenta de la doble dimensión constitutiva del género en tanto producción discursiva y material. Cabe suponer que una perspectiva que analice la doble producción de género y espacios puede generar una manera alternativa de pensar, que permita superar su respectivo entendimiento dicotómico.

En este punto se impone una advertencia. Mi ambición al trabajar en contra de la todavía poderosa dicotomía de lo "público" y lo "privado" no está motivada por la inconformidad intelectual del feminismo de la década de 1980. Carol Gilligan, por ejemplo, consideró fundamental hacer un llamado a la reintegración de las "virtudes femeninas convencionales", descartadas por los proyectos educativos y relegadas a un estatus inferior en la construcción de ciudadanos completos, responsables y morales. Gilligan sostenía que el cuidado y otras actitudes relacionales que aparecen como el sello de la feminidad, deben reconciliarse con posiciones "masculinas" de distancia y abstracción. En suma, desde su punto de vista la personalidad humana era una unidad perdida que necesitaba ser restaurada o, más bien, "re-integrada". A diferencia de este tipo de enfoques, no estoy interesada en fomentar la idea de complementariedad y reintegración de hombre/mujer 


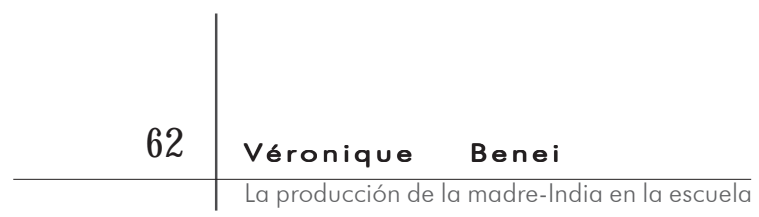

en un "todo". De hecho, mi proyecto global no busca reconciliar las dos caras de la dicotomía. En cambio, pretendo mostrar la doble producción del género en instituciones y personas, con la intención de revelar las complejidades de las comprensiones de género. En otra parte he desarrollado una reflexión más amplia sobre las modalidades de pensar el género (Benei, n. d.). De momento, me interesa documentar y desenmarañar los aspectos combinados de la producción del género y la nación en los procesos de socialización en el espacio escolar. Como lo señalan Epstein y Johnson (1998: 2): "En tanto espacios de actividad cotidiana así como instituciones públicas o estatales, las escuelas son lugares en los que se desarrollan, practican y producen la identidad sexual y otras identidades".

En la actualidad, para la inmensa mayoría de habitantes del Maharashtra la socialización ya no es un fenómeno exclusivo de los espacios "tradicionales" de la familia, la casta, la comunidad, el pueblo o el barrio: ocurre también en la educación formal, especialmente en la primaria: allí, la tasa de alfabetización alcanza casi $75 \%$ del total de la población. Ahora más que nunca, los patrones de autoridad y los modelos de comportamiento los imponen la familia -padres u otros parientes mayores-y los(as) maestros(as). Incluso desde temprana edad, la socialización de los niños está imbricada en una multiplicidad de normas y reglas culturalmente definidas (Kumar, 2001).

En este artículo intento demostrar que la producción social y cultural de las identidades regionales y nacionales en el contexto de la educación formal no sólo es fundamental en la constitución de la institución disciplinar de la escuela, para el modelado y disciplina del cuerpo y para la "normalización" de los sujetos (Foucault, 1979, 1981), sino que es co-sustancial también a la producción del discurso y la corporalidad de género. Al usar la noción de sensorium me interesa destacar la manera en que ambas producciones forman, y se forman en el "apego", el "vínculo" y las "burbujas emocionales" desarrolladas en la intimidad del hogar y la familia. Con este fin, intento reconciliar el enfoque fenomenológico con uno psicoanalítico y pragmático, por medio del registro y la descripción de lo que Husserl llamaba la evidencia (Evidenz), es decir, los contenidos mismos tal como los revelan de una manera clara y distinta los actores sociales, y con el recurso interpretativo de conceptos psicoanalíticos. La noción de incorporación adquiere un peso central en este proyecto, puesto 


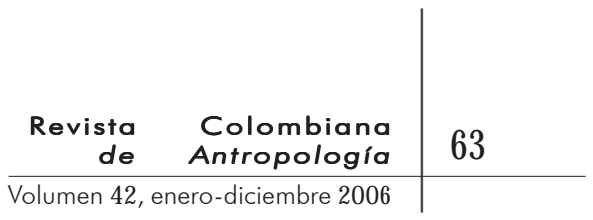

que no distingue los contenidos de los procesos mismos, sino que presume su producción mutua. Por incorporación entiendo la formación de habitus que remiten no solo a prácticas corporales, sino también a emociones, sensaciones y recursos cognitivos producidos cultural y socialmente, permitiendo la interiorización del yo. De varias maneras, la elaboración de la interioridad y la incorporación es indisociable de la elaboración de un yo colectivo nacional o regional. Más aún, tal construcción se favorece de la articulación de la figura materna en los espacios familiar, escolar y nacional. Pero también al contrario: tal construcción favorece la reproducción cotidiana de la "madre-India" y la división esperada de roles de género.

El tropo materno se presta bien para explorar las categorías de género, incorporación y sentimiento nacional. En los últimos cuarenta años, la nación se ha encarnado con frecuencia en figuras femeninas. Incluso en las décadas de 1950 y 1960, en la llamada "era Nehru", la promoción de una agenda de desarrollo nacional conoció el despliegue de la forma femenina como mediación de progreso social e industrial. La película de Mehboob Khan, La madre India, rodada en 1957, es un ejemplo sobresaliente de este despliegue. Los valores de prosperidad y abundancia que encarnaba la nación culminaron en la figura materna, alternativamente criadora y ferozmente protectora. Estos aspectos, múltiples y contradictorios en la sociedad de la India, no sólo ocupan una parte importante de la cultura popular, sino, además, en las construcciones nacionales y en los proyectos pedagógicos. En los últimos, el motivo de la madre es central para, y emblemático de, la construcción y auto proyección de la nación (Assayag, 2003). Dejando de lado cómo puede apoyar la educación la (re)producción de la maternidad en la India (Kumar, 2000), todavía debe documentarse exhaustivamente de qué manera la categoría "madre", como un marcador hegemónico de feminidad en los discursos sociales y culturales, impregna el ambiente pedagógico, en especial la escuela primaria. Con toda seguridad, esta "penetración materna” no es específica de la India, como quiera que ha sido estudiada en otros lugares. En el Reino Unido, por ejemplo, en la actualidad la escuela primaria es un espacio nacional femenino por excelencia (Woodward, 2002: 46). Sin embargo, en la India esta penetración va más allá: cabe suponer que la imagen de la "madre" es dominante en la producción de sujetos (Trawick, 1989), ciudadanos (Ramaswamy, 1998) e instituciones. 


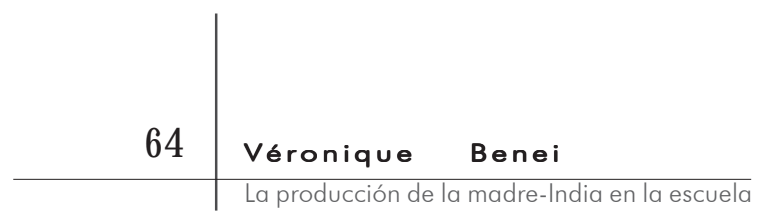

AMOR DE MADRE, VÍNCULO Y APEGO:
LA PRODUCCIÓN DE UN SENSORIUM CONTINUO

N UNA SERIE DE CONFERENCIAS ORIGINALES E INNOVADORAS DADAS EN - los años 1930, Melanie Klein, pionera de la psicología de la - infancia, trabajó sobre la idea de la "madre buena", y acerca de la importancia del contacto corporal entre la madre y el hijo (1964). Klein daba gran importancia a las funciones corporales, hasta llegar a plantear la hipótesis de que la fantasía inconsciente -que para ella también existía en el infante- siempre está basada en funciones corporales, lo que reviste una importancia fundamental no sólo para el desarrollo del joven niño, sino también para su futuro desarrollo como adulto:

\begin{abstract}
Debido a que nuestra madre fue la primera en satisfacer todas nuestras necesidades de preservación, nuestros deseos sensuales, y fue quien nos dio seguridad, ella ocupa una parte duradera en nuestra mente, aun cuando las diferentes maneras en que se manifiesta su influencia y las formas que esta adopta pueden no ser para nada obvias durante el resto de la vida (Klein, 1964: 59).
\end{abstract}

La noción de la "madre buena" o del "buen seno" es fundacional para el psicoanálisis moderno. Bajo la influencia del trabajo de Klein, Donald Winnicott desarrolló los conceptos de "cuidado" y "manejo". Dicho de una manera simple, estos conceptos ponen el acento en la construcción sensible de un entorno materno seguro y digno de confianza. El psicoanalista indio Sudhir Kakar, en una ampliación de las posibilidades de este análisis, reelaboró la noción de la "madre buena" mediante el desarrollo del concepto de la presencia sensorial de la madre y su importancia vital en las experiencias tempranas de desarrollo y descubrimiento (1999. 54). Con todo, es necesaria una gran precaución con la propuesta de Kakar, pues tiende a reificar lo "indio" en la sociedad "india”, esencializando el hinduismo, como sea que se centra en nociones problemáticas como "la psiquis hinduista" o la "mente hinduista", que con frecuencia implican, además, una ecuación problemática de lo "indio" y lo "hindú". Sin embargo, teniendo presentes estas limitaciones, sus aportes contribuyen valiosamente al desarrollo de una idea de sensorium. A diferencia de Klein, en la obra de Kakar la presencia sensorial de la madre no se limita al "seno bueno", sino que se extiende a 


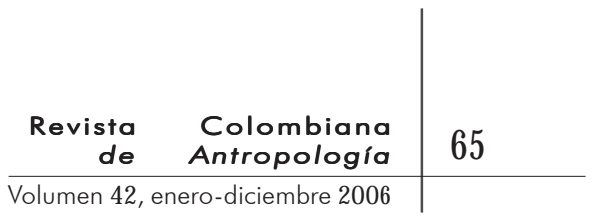

las caricias, al tacto, al habla, a las canciones, etcétera; en otras palabras, a un "sensorium primario" ampliado. Kakar prolonga también esta fase en el desarrollo del niño en la India, incluyendo las edades de tres a cinco años, cuando en la sociedad europea usualmente se suele identificar sólo en niños más pequeños. Su argumentación teórica, por otra parte, descansa en observaciones diferenciales de experiencias de separación y limitaciones. Diferencia que resulta fundamental, pues sugiere la posibilidad de un continuum experiencial más profundo entre la vida en el hogar y la vida escolar, en donde las primeras experiencias escolares -en el jardín infantil y la escuela primaria- son de incorporación de valores, normas y sentimientos ${ }^{6}$.

En otros trabajos he descrito dichos procesos de incorporación en los rituales matutinos y las liturgias políticas en las escuelas primarias maratíes (Benei, 2001). Estos procesos involucran la constitución de un sensorium, es decir, un conjunto de experiencias sensibles manifiestas en el canto, la oración, el golpe de tambores, la escucha y la calistenia, y en las cuales la métrica, el fraseo y el ritmo participan en la incorporación

6. Obviamente, esta posibilidad es muy varia ble y depende mucho del grado de convergencia ideológica existente entre la familia y el hogar, por un lado, y la escuela, por otro. Las experiencias de escolarización pueden ser perturbadoras también, en particular para los niños musulmanes educados en un contexto maratí (véase Benei, n. d., capítulos 4, y 5 principalmente). Además, aun en los casos en los que las experiencias del hogar contradicen la ideología de la madre buena desarollada más largamente en el aula, el desfase entre la experiencia vivida y el discurso poderoso en la escuela puede también generar angustia de pertenencia, que se puede manifestar de diversas maneras. de la emoción por medio de la kinestesia. La incorporación en la escuela recoge y prolonga, de diferentes maneras, el sensorium que se construye en la intimidad familiar, en primera instancia por conducto de la mediación de una figura de crianza postulada e idealizada como "la madre”, empírica -fenomenológica- y metafóricamente. En gran medida, las modalidades de crianza temprana se invocan en la escuela mediante asociaciones positivas y memorias normalizadas de la madre en el hogar. Ello por medio de un movimiento dialéctico que pasa del proyecto estatal a sus representantes en el terreno: maestras y maestros. Los libros escolares distribuidos por la oficina gubernamental de educación en el estado del Maharashtra, por ejemplo, proporcionan una evidencia interesante de esta normalización del tropo materno en el espacio escolar. Incluso el primer encuentro del infante con el mundo escrito, en el primer grado de primaria, se presenta en dichos 


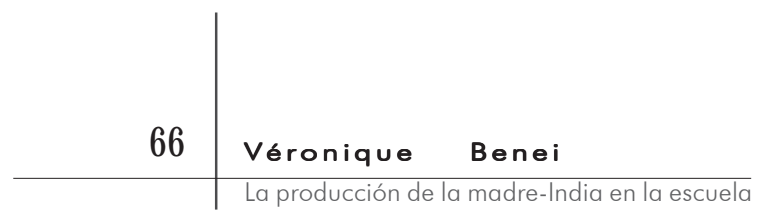

términos. El libro escolar de lengua maratí muestra a los niños dos pequeñas ilustraciones de ghar ("casa, hogar") y ai ("madre, mamá”) (p. 15). Esta última aparece abrazando amorosamente a un niño pequeño. Ambos dibujos están debajo de uno más grande que recubre el ancho de la página, en el que se representa a los niños saliendo de la escuela para su casa, y donde sobresale una madre que recoge a su hija mientras lleva otro niño colgado de sus caderas. Las palabras y fenómenos correspondientes están representados en tres líneas diferentes en el último tercio de la página. La figura de la "madre" aparece en muchas lecciones posteriores junto con su hijo en actividades diversas, como ir al mercado (p. 18), escoger frutas (p. 20), tomar un vaso de jugo de caña (p. 2I) y otras más. Referencias similares se pueden encontrar en los textos dirigidos a los siguientes tres grados de primaria.

Además del currículo oficial, las referencias a las madres hacen parte de la cotidianidad de la escuela, en la medida que a los pequeños se les recuerda continuamente su hogar y su familia: durante las lecciones -sobre todo en lengua maratí e historialas maestras o maestros, sin diferencia de género, usan con frecuencia a las madres como ejemplo. Los materiales importantes al respecto incluyen desde historias regionales, como la epopeya de Shivaji -siglo diecisiete- y su relación con su madre, hasta los cuentos populares con moraleja difundidos en todo el mundo. Los ejemplos abundan, desde Aice aikayce (literalmente "Uno debe escuchar los consejos de la mamá"), en la que se narran los problemas que tiene un niño por desobedecer a su madre, hasta relatos autobiográficos, en particular el del educador y luchador libre Sane Guruji (Shyamci Ai, "La madre de Shyam”). Además, las cualidades maternas como ideales de crianza se invocan y reproducen discursivamente de muy diversas formas. Una de ellas es mediante la referencia a la alimentación. Como es bien sabido, la comida es un objeto táctil y un mediador sensual del vínculo de la madre con el hijo. En Maharashtra las madres alimentan a sus hijos con sus propias manos hasta que alcanzan los cuatro o cinco años de edad, lo que a menudo está acompañado de juegos de ambas partes. Después de Klein, Erikson sostuvo que estas, "en apariencia cortas y juguetonas rutinas durante el primer comportamiento ritualizado en la vida”, son especialmente importantes en la medida que parecen obrar como "precursores de comportamientos de gran significado emocional y adaptativo para el resto de la vida, antesala de la ceremonia ritual” (2002: 18). 


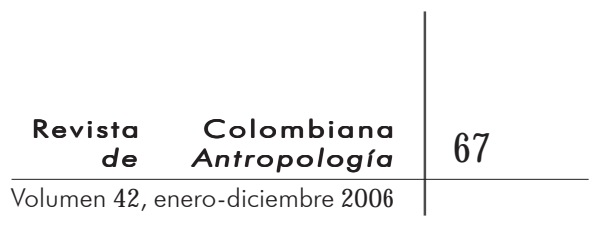

Dichos precursores son reforzados o (re)producidos en la escuela, donde los profesores hacen numerosas alusiones a la vida familiar, la rutina doméstica y la "cocina de la madre" (Aica svaipak), a lo que se espera que ella se dedique amorosamente por horas para el bienestar de sus retoños ${ }^{7}$. Incluso las lecciones de matemáticas pueden ofrecer la ocasión para tales evocaciones; por ejemplo, cuando la señora Pratima B. en Vidhyapeeth Marathi Shakha (VMS) tomó prestado un chapati de la lonchera de un alumno, con el objeto de enseñar la operación de la división en su clase de tercero -a niños de más de ocho años-, para lo cual partió el cha-

7. Una de las actividades que todavía consume más tiempo en la vida diaria de las mujeres en la India urbana es la preparación de alimentos. A pesar de la creciente disponibilidad de productos preparados, la mayoría de las mujeres de clase media y media baja en Kolhapur gasta un promedio de cinco horas al día cocinando, preparando chapatis, vegetales, arroz, chutney, etcétera, alimentos cuya preparación requiere, muchas veces, largos procedimientos.

pati en varias partes idénticas. Además, las madres no sólo impregnan metafóricamente el espacio público aun cuando segregado de la escuela. El espacio familiar se recrea retóricamente en el colegio, donde habitan otras madres: las profesoras. De hecho, en las concepciones pedagógicas está en juego una asociación cercana entre la madre y la profesora. Las profesoras generalmente se consideran mejores madres que las de los niños, y lo dicen explícitamente a menudo. Además, la ejemplificación más patente del papel maternal de las profesoras se observa también en las enseñanzas oficiales.

En este sentido, una de las narraciones más significativas que oí en el District Institute of Education and Training (DIET) en Kolhapur, es la de "la profesora y el niño". Al menos dos veces oí al director de la universidad narrarla en sus visitas de formación, y después la escuché de boca de un profesor en una escuela maratí. El cuento es muy sugestivo sobre la fusión imaginada de la madre y la profesora, y es uno de los favoritos de los(as) profesores(as). Además, habla de una relación particularmente emotiva entre una madre y un hijo varón, en la que se replica, de alguna manera, la primera fase del vínculo nacional con carácter de género: la madre criando a su hijo, antes de que este llegue a la edad de defenderla. La historia comienza el primer día de colegio de un niño. Después del almuerzo, el pequeño se acerca a su profesora y se limpia las manos con su sari. La profesora reprende al niño. Al día siguiente sucede lo mismo y la profesora lo regaña de nuevo. Al final del tercer día consecutivo 


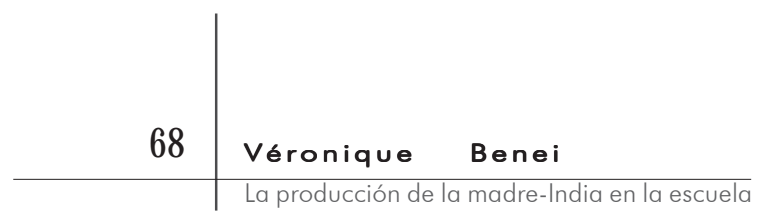

de manos sucias y saris estropeados, la profesora decide acudir a la madre para comentarle el comportamiento de su hijo. Ella le contesta que: "Así como yo soy su mamá en la casa, tú eres su mamá en el colegio, él confía en ti, tú lo cuidas, tú eres una madre para él, de ahí su comportamiento". El director de la universidad terminaba la historia exhortando a las mujeres presentes en la capacitación a dedicar a sus alumnos la misma atención y cuidados que a ellos les dedican sus propias madres. A lo que muchos hombres y mujeres del auditorio respondieron con su aprobación. Lo que por fuerza se observaba en la charla con los profesores del DIET era la transposición de la intimidad, seguridad y confianza del medio familiar en el espacio semipúblico del colegio. Es importante resaltar que estas dos cualidades, cuidado y confianza, son justamente las que Melanie Klein y Donald Winnicott, seguidos de Eric H. Erikson y Sudhir Kakar, en referencia directa a la India, han resaltado como fundamentales para el desarrollo del infante y para la construcción de su "burbuja emocional".

Es obvio que lo que se proyecta en el espacio aséptico del entrenamiento universitario de maestros y en la escuela son visiones idealizadas de la maternidad, de las relaciones madre-hijo(a) y profesor(a)-alumno(a). En estas visiones queda muy poco espacio para realidades alternativas quizá más crudas, como cuando la madre no se encuentra disponible o está en incapacidad de responder con devoción a estas obligaciones, o cuando la profesora se ausenta regularmente. Sin embargo, estas visiones hacen pensar en la convergencia del pensamiento popular -representado aquí por las maestras y maestros, y también por los padres. Véase supra- y el pensamiento escolar, de las modalidades de constitución de un entorno emocional en la escuela y el hogar.

Más aún. En la narración citada cabe notar que el sari funciona como recreación de una envoltura corporal para la profesora, pero también como una cobija gratificante para el infante, como una mediación del vínculo materno establecido inicialmente en el calor del hogar (véase Banerjee y Miller, 2003sobre los varios usos del sari en diferentes partes de la India). El sari en este contexto puede asimilarse a lo que el psicoanalista francés Didier Anzieu ha llamado "moi-peau", o "ego-piel” (Anzieu, 19851989), que define un espacio de transición y protector entre la "envoltura" corporal del niño o la niña y su entorno. De todos modos, la referida "moi-peau" sirve, en este contexto, para ilustrar la relación funda- 


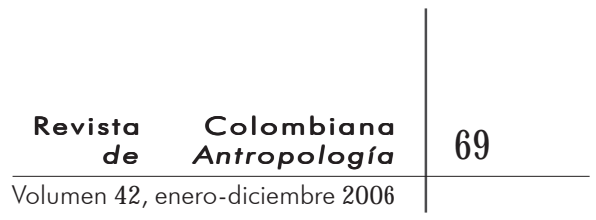

mental entre una profesora-madre y un alumno-hijo, relación evocada explícitamente por las profesoras mismas. De hecho, ellas amalgaman a menudo las nociones de maternidad y conyugal con la disciplina corporal del uso del vestido del "sari". En Maharashtra el sari es emblema del estatus conyugal de las mujeres y, por extensión, de la maternidad. En congruencia con ello, las profesoras comentan con frecuencia que "para enseñar, una mujer debe estar casada, una profesora es una madre". O: "Es nuestra cultura, nosotras debemos ser como madres en la escuela". Mediante estas afirmaciones, revelan la efectiva incorporación discursiva y corporal de una norma aún vigente en las escuelas de habla maratí: ninguna profesora puede vestir nada distinto al sari ${ }^{8}$. Dicha norma se refuerza oficialmente desde el inicio del entrenamiento profesoral: a diferencia de otros tipos de universidad, todas las dedicadas a la formación de maestros en Maharashtra han establecido el sari como el uniforme obligatorio para las profesoras, con lo que fusionan explícitamente patrones normativos de comportamiento pedagógico con la maternidad ${ }^{9}$.

Debe advertirse también que no sólo es obligatorio cualquier tipo de sari, sino el que ahora aparece como icono "clásico" de la modernidad india femenina, es decir el sawari sari ("sari de seis yardas”), que remplazó el tradicional nawari maharashtriano ("nueve yardas") en contextos rurales y urbanos, en especial en las jóvenes generaciones. En las zonas rurales, las mujeres que se han casado en los últimos quince años y cuyas madres usaban nawari saris, han adoptado el sawari. Si se les pregunta a que se debe ese cambio, responden con frecuencia: "amhala laj watte, nawari sari nesli ki" ("nos da vergüenza vestir un nawari sari"). El nawari sari adopta y revela de manera más bien evidente las formas femeninas; el paño se pasa entre las piernas y se amarra en la espalda, dejando descubiertas las pantorrillas. Aunque

8. En este contexto los códigos del vestido funcionan como un campo de «simbolización». Debo subrayar que cuanto presento a discusión atañe sólo a las escuelas de habla maratí. Las de habla inglesa son poco numerosas en Kolhapur y sirven a una minoría de niños(as) en edad escolar, a menudo desde una educación más cosmopolita. Las profesoras que trabajan en estos colegios se enorgullecen con frecuencia de disponer de mayor libertad en el código de vestuario. La mayoría de ellas usan vestidos panyabíes, es decir, un pantalón amplio cubierto con una larga camisa, sin importar su estatus marital.

9. Más adelante se verá cómo opera esta amalgama en la conceptualización de la nación, en la asociación de la madre con el país. De momento, el lector puede remitirse a la dimensión simbólica de la "bandera-sari" con que vestían en 1999 y 2000 las mujeres y profesoras en Kolhapur y otros lugares en Maharashtra (Benei, n. d., "Introducción"). El simbolismo de la bandera-sari y su funcionamiento como envoltura corporal acrecienta la producción de significado para un sensorium primario nacional. 


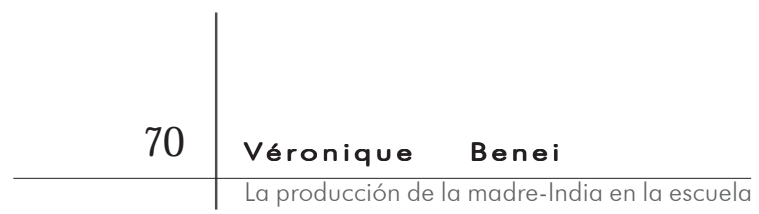

es mucho más práctico que su versión más reciente para una "vida moderna activa", como lo señala el comercial, en cuanto permite mayor libertad de movimiento para montar en cicla, moto o subir a un bus, deja más descubierto el cuerpo femenino frente a la mirada pública. En contraste, el sawari sari trata de esconder mucho más, cubriendo por completo la parte baja del cuerpo. En especial en el medio urbano y en el trabajo, las mujeres tratan con austeridad de abrochar el borde (padar) a la blusa que le combina, en gesto de preservar el recato moderno. Aquí está en juego una interesante convergencia entre los idiomas de la modernidad y la moralidad victoriana en la producción de una respetable maternidad y "profesoralidad", semejante a la que ya ha sido documentada en los proyectos de construcción nacional (Gupta, 2001). Esta convergencia es más explícita hoy en día en el espacio escolar que en ninguna otra parte.

La amalgama entre "madre en el hogar" y "madre en la escuela" no sólo se hace manifiesta, sino que también se naturaliza, de nuevo, por medio del canto. En Maharashtra, al menos desde el siglo diecisiete, las madres han sido asociadas a un gurú vivo, aun cuando la mayoría de ellas no haya recibido ningún tipo de entrenamiento. Por ejemplo, el famoso poema Guru Brahma guru Vishnu..., escrito por el poeta ma-

* Todas las traducciones de canciones e himnos maratíes fueron realizadas a partir de la traducción inglesa de la autora. Nota del traductor. ratí Ramdas, ilustra esta ecuación de la madre con el gurú. La traducción de la segunda parte de la canción dice*:

Mi madre es mi gurú, ella es el árbol que me concede los deseos (kalpataru)

Ella es el océano de felicidad; ella es el maher [residencia natal familiar de una mujer casada] de amor

Ella es la corriente de vida eterna (amrut); mi madre es la esencia del bien.

Durante los últimos quince a veinte años, esta canción se ha cantado en algunas escuelas maratíes de Kolhapur-como es el caso de Vidhyapeeth Marathi Shala (vMs) y de la New Highschool Marathi Shala (NHMS), dos escuelas que simpatizan mucho con el hinduismo político en Kolhapur-y de manera más reciente en otras. Este poema se canta a diario, con frecuencia en las reuniones matutinas, ya sea en el pasillo o en cada uno de los 


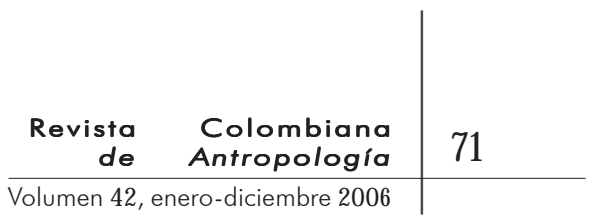

salones. Es sin duda interesante que sea por la mediación del concepto de gurú que la asociación de la madre y la profesora parezca producirse "naturalmente" en niños(as) y profesores(as). Así, por ejemplo, cuando una profesora de segundo nivel en un curso de niñas -mayores de siete años- en NHMS intentaba explicar en noviembre de 2000 el significado de dos cantos acerca de la madre y el país (véase más adelante), preguntó: “¿Quién es un gurú?", las dos respuestas que recibió inmediatamente de sus alumnas fueron, primero, "Dios (Dev)”, y después "La madre (ai)”. La profesora preguntó entonces; "¿Por qué? ¿Por qué la madre es gurú?”. Luego de un silencio largo y perplejo en el salón, ella misma ofreció su respuesta: "Porque ella da vida. La madre y Bai [término empleado para dirigirse a las maestras, semejante a señora], ambas dan vida. La madre enseña en el hogar, ella les da alimento, y la señora [Bai] continúa el trabajo en el colegio y les enseña correctamente". La clara articulación de la relación entre divinidad y maternidad es importante con respecto a la imagen "generizada" de la nación india, Bharat Mata.

\section{Espacio doméstico, Espacio NACiONAL: PRODUCCIÓN DE GÉNERO \\ Y DE LA MADRE INDIA EN LA ESCUELA}

L

A COMBINACIÓN MADRE-PAÍS ES UN MOTIVO CENTRAL EN LA EDUCAción de los(as) niños(as) en el promedio de las escuelas maratíes. Atraviesa las tendencias políticas, desde las escuelas más "seculares" hasta las de línea hindutva, donde la amalgama puede encontrarse exacerbada. Más aún: la combinación conceptual de maternidad, devoción y pedagogía hace eco de la reelaboración eriksoniana de la argumentación de Klein, que señala que "la capacidad de identificación con otra persona [o deidad] es un elemento principal en las relaciones humanas en general, y es también una condición para sentimientos de amor fuertes y reales" (1963 66). Para Erikson, el elemento central de la ritualización de la infancia, que él llama lo "numinoso", permanece estrechamente asociado con la devoción ritual, ya sea en la religión institucionalizada o en otro tipo de sistemas de creencias (2002: 19). Ello es importante, pues si la maternidad es uno de los aspectos comúnmente empleados por varias ideologías 


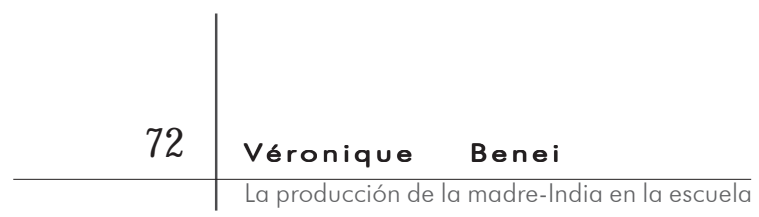

-desde totalitarias hasta liberales (véanse Koonz, 1987, para el régimen nazi, y Berezin, 1997 para el fascista)-, que la presentan como fundamento constitutivo y expresión emblemática de la familia, en la India, como hemos visto, este emblema es todavía más poderoso para los grupos hindúes: el país (desh) mismo es concebido como una figura materna y una diosa (hindú). La India es, de hecho, "la madre India" (Bharat Mata).

Bharat Mata es el resultado visible de negociaciones coloniales realizadas en otras partes de la India, en particular Bengala. La ilustración más famosa e influyente de estas negociaciones es tal vez la famosa novela de finales del siglo diecinueve de Bankim Chandra Chatterji, titulada Ananda Math (1882), célebre por su tono fuertemente anti musulmán, aun cuando ello ha sido reconsiderado por Julius Lipner en su introducción a la nueva traducción inglesa publicada en 2005 La narrativa de la novela debe situarse en el contexto de la producción de la nación india en tanto entidad geohistórica: la imagen de Bharat así como esta entidad geohistórica concreta sólo se pudieron naturalizar progresivamente, con un mapeo territorial generizado: producir la nación implicaba al tiempo "naturalizar" una abstracción y dotarla de "corpo-realidad", "para lo cual no era descabellado apelar a la figura de la madre" (Goswami, 2004: 199). Tal tropo moderno podía obrar como un "orden tradicional, orgánico" en el que Bharat Mata "representaba la matriz fundamental del anhelo y la identificación nacionalista" (Ibídem). Lamentablemente, incluso en lo que se refiere al nacionalismo popular, el repertorio referido ha pertenecido exclusivamente a la casta superior y a las prácticas devocionales del norte hindú de la India. Ello ha implicado desatender el advenimiento de dicha "generización", aparte de una primera aparición en una obra de teatro hindi en 1876(Ibídem), así como los demás repertorios de prácticas populares que favorecieron esta construcción. Sin embargo, las condiciones de producción de dicha encarnación exigen atención, aun cuando sea sólo porque la imagen de Bharat Mata fue objeto de enfrentamientos políticos entre hindúes y musulmanes en la última parte del siglo diecinueve y las primeras décadas del veinte. Más notorio aún, en las décadas posteriores a la independencia este conflicto ha cristalizado con mayor vivacidad el deseo nacionalista entre los hinduistas de clase media y media baja.

Como ocurrió con la reconfiguración del espacio del estado colonial en tanto nación como madre, la Bharat Mata posinde- 


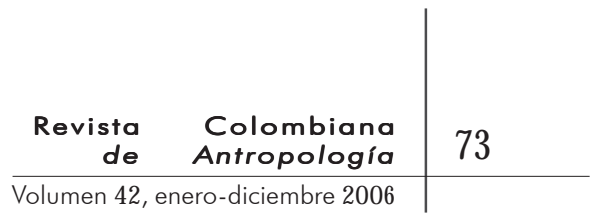

pendentista se basa en "el deslizamiento constitutivo de las relaciones madre-hijo y el deslizamiento de las relaciones entre el devoto y la divinidad en las prácticas devocionales populares hindúes" (Goswami, 2004: 202). La ecuación crucial "madre-deidadpaís" desde el primer momento de la India como nación moderna, está ejemplificada claramente en la canción que por un tiempo fue considerada como himno nacional de la India: Vande Mata$\mathrm{ram}^{\mathrm{D}}$. La canción, cuya letra apareció por primera vez en la obra de Chatterji, está dirigida a la India concebida como una madrediosa (hindú) ${ }^{11}$. Aunque grupos musulmanes y seculares se han opuesto a ella durante largo tiempo, en Maharashtra se la canta en ocasiones especiales, como durante las conmemoraciones nacionales. Recientemente Vande Mataram se ha vuelto más importante para un creciente número de escuelas maratíes de Kolhapur. Como en el resto de Maharashtra, incluyendo a Mumbai, alumnos y profesores acostumbran terminar el día escolar con la canción del Pasaydan. Esta, que es un extracto del Dnyaneshwari, se basa en un poema épico que a su vez toma su nombre de su autor: Dnyaneshwar, un santo regional popular y poeta del siglo trece. A pesar de su gran popularidad y tradicionalismo, el Pasaydan ha venido siendo reemplazado por Vande Mataram. Esta última la escuché cantar por primera vez en un colegio privado (Vikram Prarthamik Shala) en Kolhapur, en agosto de 1998 A finales de 1999 ya se había difundido ampliamente en la red escolar y se cantaba también en otros colegios privados y corporativos, tanto en las asambleas colectivas -lo que sin embargo era raro- como en los salones de clase. La resonancia creciente de este controvertido himno puede haber sido el resultado de la organización sistemática de cursos de nivelación para maestros de escuelas primarias en Maharashtra durante mediados y

10. Se canta en las escuelas al inicio de la jornada, así como fuera de ellas. En la época de la independencia, Vande Mataram era para muchos, entre los que se encontraba Gandhi, la canción nacional por excelencia, debido a su asociación ya tradicional con el movimiento de liberación. Sin embargo, para otros, entre los que se encontraban los musulmanes y otros grupos seculares, era vista como una canción profundamente comunitaria. Vande Mataram fue primero descartado como himno en favor de Jana gana mana. Esta canción describe las regiones de la India (véase Benei, n. d. capítulo 1 .

11 Sólo las dos primeras estrofas se consideran el himno nacional:

(I) iMadre, me inclino ante ti! / Rico de tu apresurado raudal, brilla con huertos relucientes, / Frío de tus vientos de deleite, ondean campos oscuros Madre de fuerza, / Madre libre.

(2) Gloria de sueños de luz de luna, Sobre tus ramas y corrientes señoriales, / Vestido en tus árboles florecientes, Madre, dadora de alivio, írío bajo y dulcemente! / Madre, beso tus pies, hablando dulce y bajo / Madre, me inclino ante ti. 


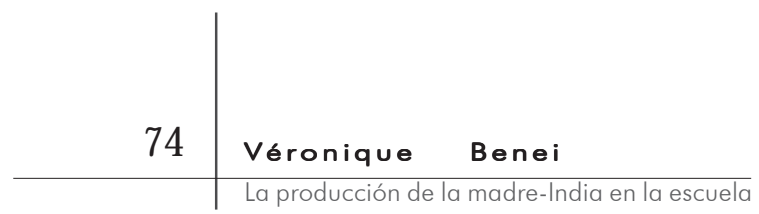

finales de la década de 1990, durante el gobierno de extrema derecha hindú de coalición Shiv Sena/BJP, aunque un número significativo de maestros y padres en Kolhapur asegura haberlo cantado con frecuencia en su época de estudiantes. Como quiera que sea, es significativo sin duda que la devoción (hindú) a la patria nacional ha superado en la actualidad la devoción regional.

Más aún. La combinación de figuras femeninas domésticas, devocionales y nacionales es consistente con las expectativas oficiales, y de manera explícita se la inculca en el District Instruction and Education Teaching College de Kolhapur. Para numerosos actores sociales en esta parte de Maharashtra, estas expectativas son igualmente significativas. Ello puede demostrarse tomando como muestra una de las sesiones de la tarde de un "curso de nivelación de canto" que tuvo ocasión en febrero de 2000. El instructor principal era Mr. Biradarkar, antiguo director de un colegio privado en Kolhapur, quien además había estado afiliado a la división local de la RSS. Luego de hablar de gestos y canciones de animales, pasó a narrar un "cuento con moraleja" (boddh katha) acerca de dos niños dejados a su libre albedrío. Uno de ellos no atendió a los consejos de sus padres y como consecuencia se metió en problemas, en tanto que el otro, virtuoso, fue aclamado como paradigma para la emulación de los oyentes. El instructor concluyó el cuento haciendo énfasis en la moral que los maestros debían inculcar a los menores a su cuidado, diciendo: "Es necesario inculcar en los niños esta moral, enseñarles que deben amar a sus madres (aivar prem [thevayce])". Después de reiterarlo, el señor Biradarkar añadió, "Así, de la misma manera (ellos deben amar) a la madre India, ellos deben aprender a amarla" (Mag tasec, Bharat Matevar prem, shikayce). Temiendo que la identificación de la madre y la nación así como la naturaleza obligada del amor que supuestamente ambas deben hacer surgir no fuera suficientemente explícita, el instructor recurrió a una demostración enfática y ferviente de lo que debe ser la liturgia matutina: tras una canción sagrada que debía ser cantada todos los días "Mi madre es mi gurú" (Ai majhya guru, véase más adelante), continuó con el himno nacional (rashtrageet), deteniéndose en él para explicar detalladamente su sentido y la forma en que se debía enseñar. Luego, Mr. Biradarkar recitó la promesa de lealtad nacional (pratidnya), con énfasis en cada una de sus palabras, a lo que siguieron una serie de canciones nacionalistas en hindi y maratí. La primera de estas llevaba el título de "Victoria 


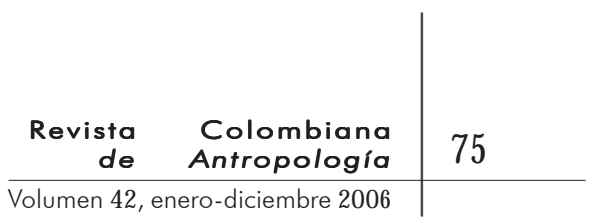

de la madre India" (Bharat Mata ki Jay) y la última "La madre India" ("Bharat Ma ") ${ }^{12}$. En esta el coro dice: "Canten, la victoria de la madre India (3)” (Bolo Bharat Mata ki Jay) (Harlekar, 1983 15). A juzgar por el lenguaje corporal de la mayor parte de los asistentes al curso, el discurso del instructor fue un éxito, aun cuando es claro que no todos los maestros y maestras se interesaron de manera igual en las canciones. Sin distinciones de género, algunos mostraban un entusiasmo más ardiente que otros. Y, sin embargo, llegada la hora de acompañar las canciones con los coros citados, bien sea como un automatismo o como un acto voluntario, todas y todos participaron de la misma explosión de energía colectiva de estas reiteraciones.

Las reiteraciones son parte importante del proceso de incorporación que trato de documentar en este trabajo, y su comprensión requiere mayor elaboración. De hecho, la incorporación requiere el desarrollo de la capacidad de reiterar, de articular voces: las canciones son en este sentido tópicos importantes para la constitución del sensorium primario, tal como los gritos y las exclamaciones, en especial lo que en la jerga psicoterapéutica, a partir del trabajo de Arthur Janov (1970), se conoce como "el grito primal”. Al respecto resulta significativo que en el promedio de las escuelas maratíes las reiteraciones más conspicuas de devoción a la nación ocurran durante el canto y la oración a la existencia de "la madre India”, pero también, de manera congruente con la mitología hindú, cuando se invoca el aspecto de ferocidad guerrera de la diosa madre. Por esta capacidad es que ella protege al país y recibe la

12. El veterano instructor aseguraba haber aprendido esta canción en 1970. Con certeza, esta fecha no es coincidencial, pues precede a la guerra desatada por la India contra Pakistán en apoyo del surgimiento de Bangladesh en 1971

13 De hecho, una traducción más común diría "Victoria a la madre India", pero de esta forma se perdería la interacción vernácula de la discursividad entre maestro(a) y alumnos(as). promesa de lealtad de sus hijos, sin diferencia de edad. Después de cantar Vande Mataram, en las escuelas de Kolhapur, el(la) maestro(a), suele inquirir a sus alumnos:

"Digan: ¿de la madre India?”

"iLa victoria!"
(“iBola: Bharat Mata ki?)”. (“iJay!)”"13,

responden los(as) niños(as), gritando y cerrando sus puños prontamente, tal como se les enseñó en las sesiones matutinas diarias. Posiblemente, el maestro(a) diga para finalizar 


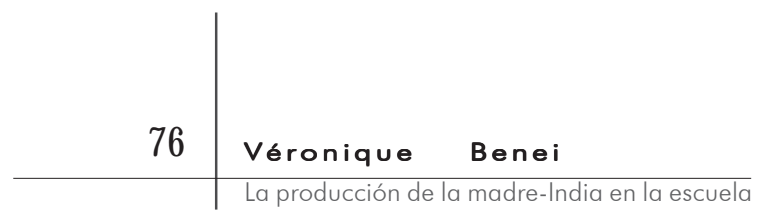

“¿Vande?”, a lo que el coro infantil responderá "iMataram!”"14. La importancia del "grito primal" es tal que en algunos de los salones

14. Este diálogo al parecer es común desde hace unos quince años en algunas escuelas, $y$ era una práctica reconocida en el nivel oficial, como pudo comprobarse en el DIET. de clase del mismo colegio (NHMS), en particular en los cursos menores, sólo se grita Bharat Mata ki Jay al final del día escolar.

La repetición diaria de estos temas alimenta también las reiteraciones en eventos extra escolares como las presentaciones anuales. Así, en el espectáculo organizado por el jardín infantil del Vidhyapeeth Marathi Shala en febrero de 1999, la última representación tenía como tema los "soldados del Kargil". Quince niños de cuatro años vestidos con uniforme de soldado marcharon en el escenario con la música de Vande Mataram, cortando las cabezas de enemigos imaginarios y matándolos de diversas maneras. La representación terminó con el siguiente intercambio de exclamaciones entre las maestras del jardín y los niños, quienes respondían en cada ocasión alzando sus puños:

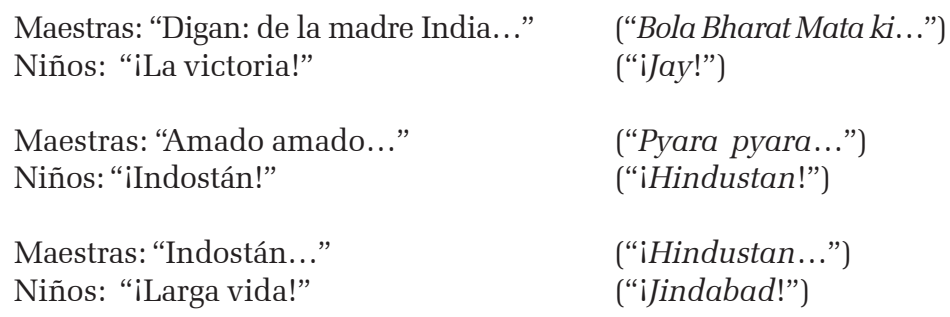

En este proceso se busca una doble incorporación: de género y también del sentimiento nacional. Pero este sentimiento requiere de una elaboración a la luz de la idea de "grito primal". En su libro seminal, Janov discutía la idea central del sufrimiento psicoespiritual, que es a menudo un sufrimiento encubierto. Distinguía tres niveles de ocurrencia de las experiencias traumáticas, donde el segundo y el tercer nivel están relacionados respectivamente con la adolescencia y la edad adulta. Las experiencias del primer nivel, que han sido las más controvertidas y debatidas en la teoría de Janov, están asociadas con las experiencias de privación en la temprana infancia, y, de manera igualmente crucial, con los traumas del proceso del parto así como con varias experiencias de angustia intrauterina. A pesar de que 


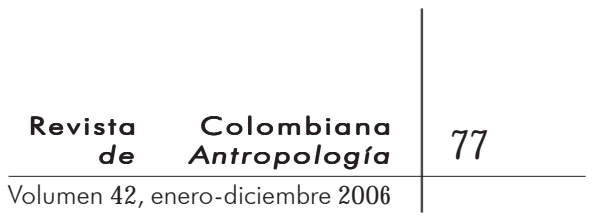

en la actualidad Janov sigue siendo considerado el precursor de estas ideas, sus planteamientos pueden situarse en una genealogía que remite a la obra de Otto Rank, uno de los primeros discípulos de Freud. Aunque Freud nunca dio mucho peso a las ideas de Rank, el discípulo no se desanimó en su convicción acerca de la realidad del trauma del nacimiento y se dedicó a idear un psicoanálisis enfocado en este proceso (Rank, 1957). Sin embargo, la obra de Rank, escrita en 1924, permaneció en la periferia de las principales corrientes psicoanalíticas, incluso para la época en que Janov escribió sus trabajos, medio siglo después. Recuperando y reelaborando las sugerencias de Rank sobre el trauma del nacimiento, Janov puso en el centro de su enfoque teórico la necesidad de ser amado y los tormentos resultantes de la insatisfacción de esta necesidad. Como terapia, desarrolló la famosa "scream theraphy" (terapia del grito primal), que ha evolucionado en diversas variantes. Aun cuando no conozco ninguna experimentación con este tipo de psicoterapia en India, el trauma del nacimiento no es exclusivo de los países euroamericanos ni está relacionado exclusivamente con las prácticas obstétricas de estos países. En especial entre las clases medias de la India, la creciente medicalización de las prácticas ha aumentado la probabilidad de nacimientos traumáticos (comunicación personal de Henrike Donner, 2006; véase también Parry, 1994, acerca de las angustias de la vida embrionaria). El objetivo de esta aclaración es arrojar luces sobre la "matriz de identificación y deseo nacionalista" (Goswami, 2004) que ha atravesado muchas vicisitudes desde su reconfiguración a finales del siglo diecinueve y en especial a mediados del siglo veinte, en los años de la partición de la India. Podría decirse que lo que indican y, al tiempo, intentan curar las exclamaciones y otras reiteraciones repetidas diariamente por los(as) niños(as) y por los adultos en el espacio de reconstrucción nacional que es la escuela, son los traumatismos imbricados de sus propios nacimientos junto con los de su propia nación. En la misma medida en que la nación se produce y existe en sus propios cuerpos, puesto que los niños la re-crean cada mañana con canciones y ejercicios físicos, gritar al unísono permite conjurar los dolores, sufrimientos y ansiedades del propio nacimiento, al tiempo que los de la naciente nación. Más que meramente inscribir la nación en sus propios cuerpos, en realidad están correspondiendo a sus dolores y sufrimientos con amor y deseo. 

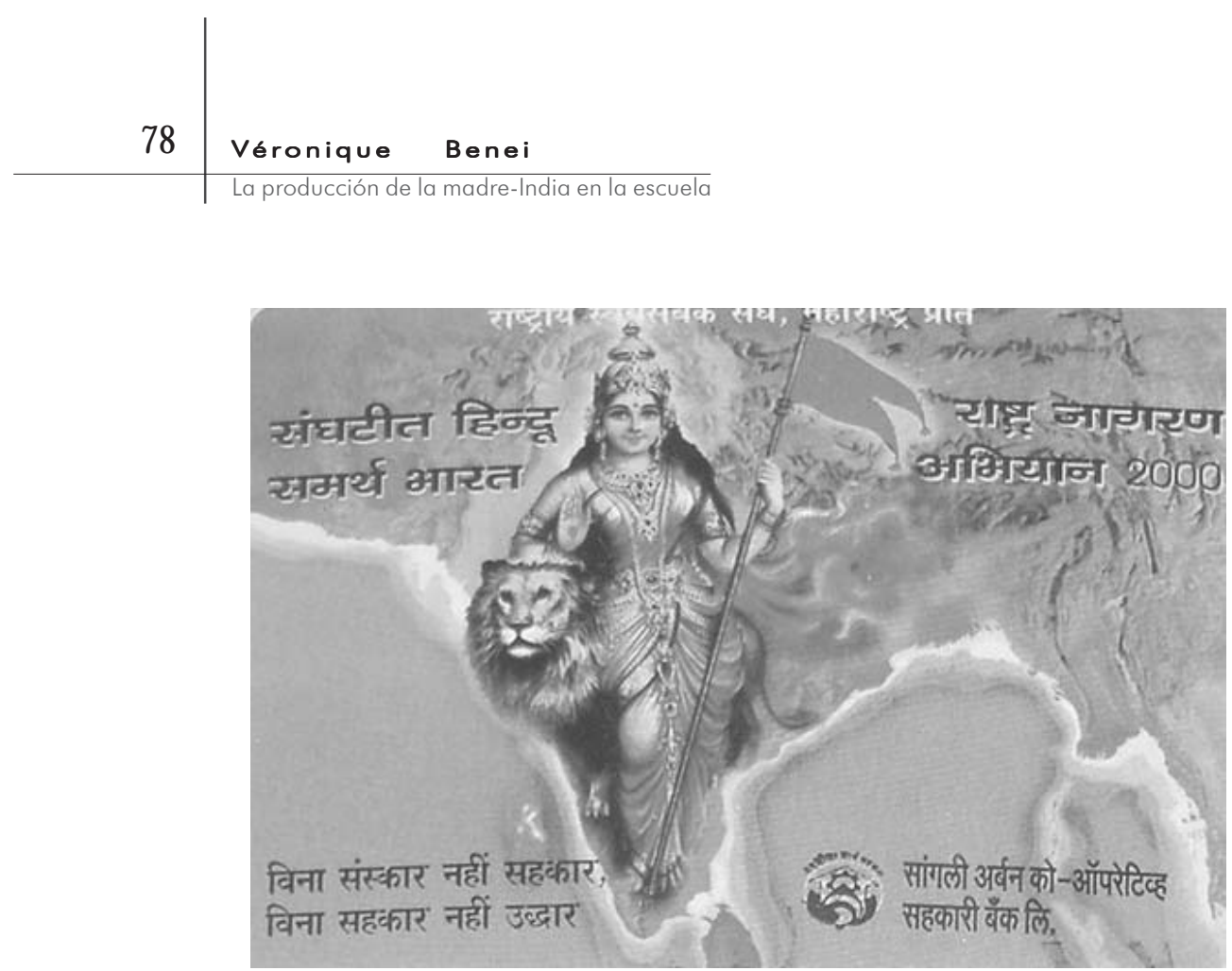

Sticker de Bharat Mara utilizado en la campaña Rashtriya Swayamsevak Sangh de 2000.

MAdRE, PAÍS Y NIÑOS(AS):

EL PODER PERFORMATIVO DE LA TAUTOLOGÍA

RENTE A LO ANTERIOR, CABE PREGUNTARSE, ¿QUÉ HACEN LOS ALUM-

- nos con todo esto? Antes de responder es necesario hacer algunas clarificaciones teóricas y metodológicas. La reconciliación del enfoque fenomenológico con un abordaje psicoanalítico y pragmático significa adoptar un marco teórico que permitiría la comprensión de los procesos de pensamiento de los actores; pero aquí me interesa más bien restituir la textura extraordinariamente compleja y rica de la acción social y cultural humana. Persiguiendo este fin, la antropología social y cultural puede presentar los inconvenientes de la incertidumbre, pero se trata de un riesgo que reconozco, y trato de evitar, mediante la verificación cruzada de los discursos y las prácticas de los actores sociales en una multiplicidad de contextos y situaciones, así como en varios momentos en el tiempo. Con esta perspectiva abordo la cuestión del sentido y la significación para los niños de lo que cantan, recitan y repiten.

Muchas de las canciones y oraciones repetidas por los alumnos en una escuela maratí promedio hacen referencia a la madre 


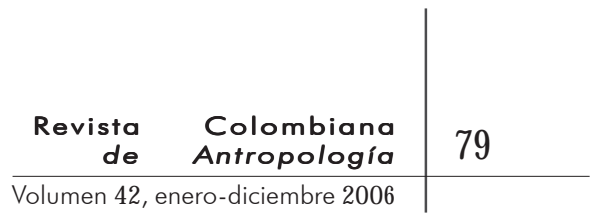

India (Bharat Mata). Pero, ¿qué significa y qué entienden los niños de esta "Bharat Mata"? ¿Cómo y en qué circunstancias se relacionan con "ella"? Este problema es particularmente importante toda vez que Mata en maratí tan solo se usa para designar diosas, a diferencia del hindi, en el que el término significa también "madre", como en la frase mata-pita15. Y este sentido único, precisamente, pone en cuestión la posibilidad de que los alumnos(as) establezcan una conexión entre "India" y "madre" (ai) en la cotidianidad. La evidencia recogida en los cuatro primeros niveles de primaria revela que la mayoría de los alumnos(as) compartían al menos una vaga idea de esta conexión. Pero si su noción de "patria" aún no estaba articulada de manera muy clara, la de sus profesores(as) sí, y ellos(as) manifestaban con frecuencia su deseo de hacerla explícita. En este proceso lo que se "representaba" y alimentaba informalmente luego era la lealtad verbal a la familia y al país, un amor incondicional a la madre y a la patria reunidas. Por ejemplo, una sesión en la New High School Marathi Shala, a poca distancia del frenético corazón de la ciudad, ofrece un testimonio de los efectos producidos por acciones performativas de este tipo. El intercambio ocurrió en la clase de la señora Sonya M., cálida maestra de unos cuarenta años, de acuerdo con el siguiente patrón: yo hacía preguntas en maratí a las alumnas -el curso era de segundo grado, todas eran niñas de siete años o más-, y ella repetía mis preguntas, aclarándolas o ejemplificándolas ${ }^{16}$. Así, por ejemplo, cuando comencé recordándoles a las niñas el modo en que iniciaban el día escolar, con el canto del himno na-

15 Mientras que en la mayoría de los idiomas del norte de la India Mata puede ser empleado como "madre", en maratí el término para madre es ai.

16. En tales situaciones, las ayudas voluntarias de la maestra fueron una parte importante en $\mathrm{mi}$ interacción con los niños. Más aún, soy consciente de que mi presencia y mis preguntas pudieron contribuir a realzar una conciencia de sentimientos nacionales. Sin embargo, las clarificaciones voluntarias de Sonyabai permitieron ver ramificaciones y asociaciones que de otra manera hubieran permanecido no verbalizadas en la mayoría de las situaciones cotidianas. cional (Jana Gana Mana), Sonyabai repitió mis palabras de múltiples maneras diferentes. A lo largo de todo el intercambio, ella repetía también, aprobándolas, cada una de las intervenciones de las alumnas. En seguida les pregunté:

“Luego de cantar el himno nacional, ¿qué dicen?”.

La maestra repitió la pregunta, separando las palabras y enfatizando: "¿Ustedes cantaron el himno nacional, cierto? ¿Jana Gana Mana, cierto? Y después, ¿qué es lo que dicen?” 


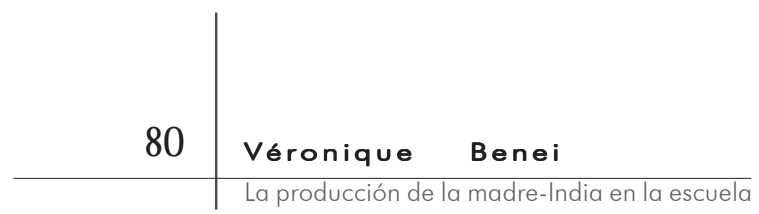

Varias alumnas respondieron en coro: "El juramento (pratidnya)". VB: "No, antes de eso, justo después de cantar el himno nacional". Sonya Bai repitió varias veces mi pregunta, pronunciando las palabras con voz fuerte y clara. Un grupo de estudiantes empezó a cantar el himno, pero fueron interrumpidas rápidamente por la maestra, quien repitió otra vez la pregunta, ayudándoles al punto de casi darles la respuesta.

De pronto, varias alumnas dijeron, al tiempo: "iVictoria a la madre India! (iBharat Mata ki Jay!)”. Algunas alzaron sus puños automáticamente, como lo hacen en la asamblea de la mañana.

vB: “¿Qué quiere decir?”. “¿Qué significa “Bharat Mata ki Jay”?”, repitió la profesora.

Una estudiante respondió: "Está en maratí". La frase, como muchas otras, está en realidad en hindi, pero también es empleada en el habla maratí17.

Otra dijo: "Bharat Mata es nuestro país (desh)”.

vB: “¿Y “Jay”? ¿Qué es?”. La maestra repitió: "Bharat Mata es nuestro país, ¿pero qué significa "Jay”? ¿Qué es “jay”?”.

Una niña, Purnima R., dijo: "'Jay" es nuestro tricolor (triranga)", refiriéndose a la bandera nacional.

Para entonces la maestra empezaba a perder su paciencia. Intentando aclarar los significados para las alumnas, comenzó a pasearse arriba y abajo del salón, mientras hablaba con voz enérgica y clara, atrayendo la atención. Su lenguaje corporal reflejaba su concentración y su tensión. Las niñas, que se estaban impacientando, se quedaron en silencio de nuevo.

Sonyabai: “¿Nuestro país (desh) es Bharat Mata, cierto?”.

Las niñas respondieron, con diligencia: “iSí! (iHo!)”.

La maestra: "Llamamos a nuestro país "madre” (ai), ¿no es cierto?”. En respuesta, de nuevo las niñas corearon con la misma diligencia: "iSí!”.

La maestra: "Bien, y nosotros reverenciamos a nuestras madres, ino es cierto? (Jayjaykar karto, aila)”.

El término jay -o en su forma duplicada- abarca los sentidos de "conquista, victoria y triunfo". De manera significativa, se usa primero que todo para las deidades -como en la expresión

17. Acerca de la relación de los hablantes maratíes con el idioma hindi, y los eslóganes, véase Benei (2000). Aun cuando en el estado de Maharashtra a los alumnos no se les empieza a enseñar el hindi sino a partir de quinto grado -mayores de diez años-, tienen muchas ocasiones para escuchar el "idioma official" debido a la popularidad de las películas en hindi que emite con regularidad la televisión y que se proyectan en las salas de cine de la ciudad a lo largo del año. Las familias de clase media urbana son, en general, grandes consumidoras de estas películas, ya sea en la casa, por medio de la televisión o de manera cada vez mayor del video, o en las salas de cine, con la consecuencia de que los niños permanecen expuestos a ellas y, por ende, al hindi. 
"Jay Vithoba"- y para referirse a héroes, guerreros y soldados, desde Shivaji en el siglo diecisiete hasta los soldados de la guerra de Kargil a finales de la década de 1990. Por extensión, la frase "jayjaykar karne" significa "celebrar los méritos de alguien (o algo), exaltar con aclamaciones y gritos". El uso de una frase como esa en este contexto ilustra de manera vívida la asociación intrincada de maternidad, divinidad y guerra. A la pregunta formulada las alumnas corearon, una vez más: “iSí!”.

En seguida, Sonyabai explicó que los cantos Vande Mataram y Pahila Namaskar-que contiene alusiones separadas a la madre y al país- tratan acerca de "la misma cosa: la 'madre' y el 'país"” 18. Dado que al parecer ninguna alumna entendía el significado de ninguna oración/canción, la profesora me llevó aparte para indicarme, en tono apologético, que cuando era pequeña ella tampoco entendía los significados, a pesar de que también repetía las oraciones a diario. Tras sus explicaciones, continuó la charla con las alumnas en torno al significado de "patriotismo" (deshbhakti,). Con el fin de ejemplificar el problema, les preguntó: "¿Por qué cantamos canciones acerca de nuestro país (desh)?”. En ese momento, Purnima alzó rápidamente su dedo y, en una asociación lógica perfecta con el diálogo anterior, dijo: "Por nuestra madre".

18. Pahila namaskar (literalmente, "Primer saludo") es un canto congruente con la ideología hindutva, debido a su sobresaliente incorporación fenomenológica del amor a dios, la familia, la maestra y la tierra natal combinadas. Sólo la escuché cantar en los colegios privados cuyas sociedades fueron originalmente fundadas por brahmanes. En esos colegios la interpretaban todos los alumnos desde primero hasta cuarto grado, cada día en las mañanas, ya fuera en el momento de las lecciones morales colectivas o inmediatamente después, por separado en las aulas. Pahila namaskar es un canto compuesto por cinco estrofas, una a una dedicadas a Dios, la madre, el padre, el maestro y la patria, o de manera más precisa, "la tierra natal" (janmabhumi). Nadie en los colegios donde se cantaba pudo precisar con exactitud su autoría. De acuerdo con un profesor universitario, Mr. Patil, su composición, sintaxis y léxico -tiene más palabras en maratí que en sánscrito-corresponden a una creación reciente, escrita posiblemente hace unos cincuenta o sesenta años. A pesar de que la cuarta estrofa hace evidente que la canción estaba destinada para ser interpretada en las escuelas, Mr. Patil -para entonces en medio de sus cincuenta años- nunca la había tenido que cantar siendo estudiante. Las líneas dicen así:

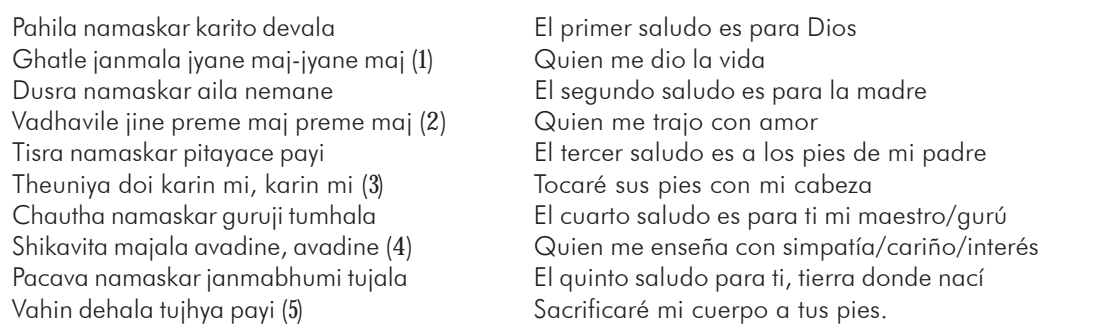



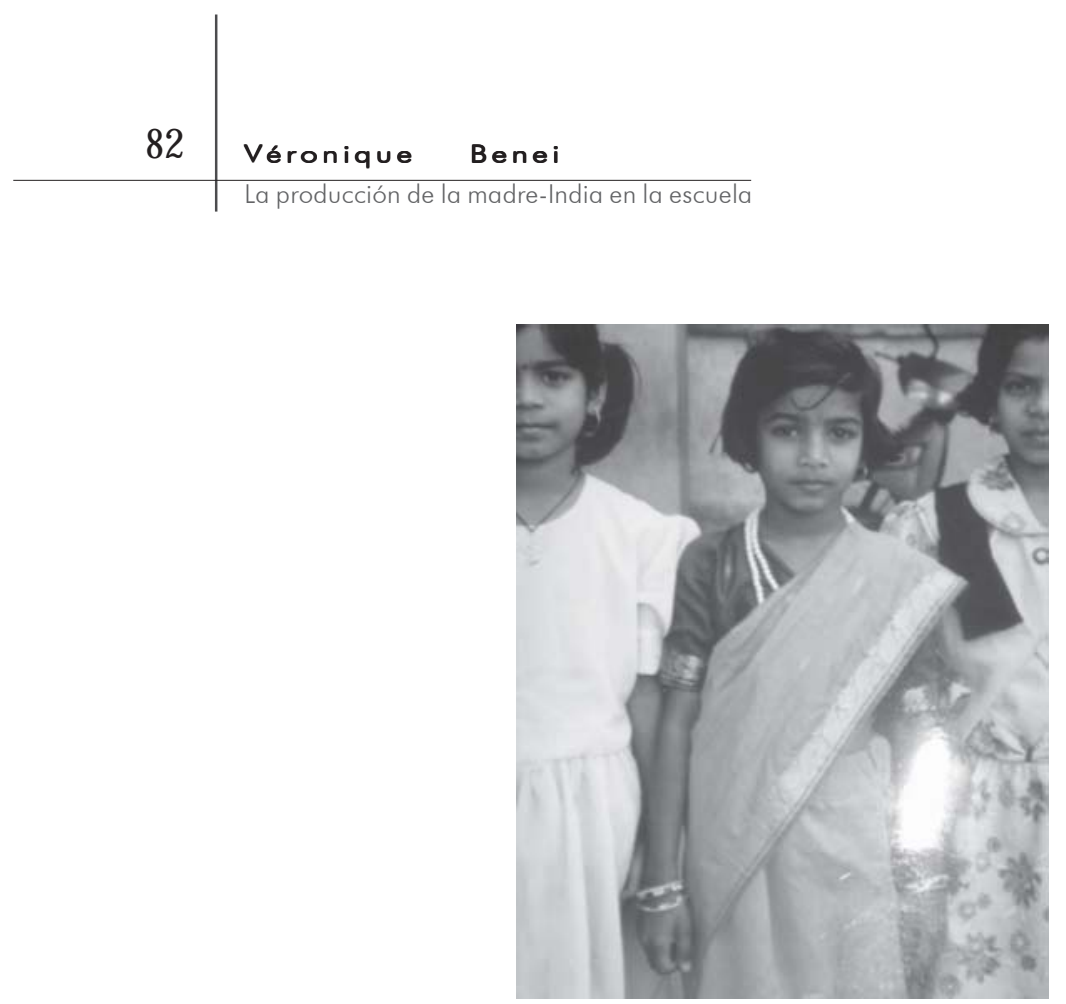

Niña de cumpleaños vestida con una bandera-sari que combina los colores verde y azafrán de la bandera nacional de la India.

Afirmar a partir de esta y otras anécdotas que Purnima y sus compañeras de clase en realidad conciben a Bharat Mata como madre es, obviamente, difícil. En ningún momento de la investigación, ningún estudiante o niño verbalizó explícitamente una asociación tan cercana. Con todo, el que de alguna forma emerja una asociación de "su propia madre" con el país (desh), aun cuando muchas veces sea confusa, es suficiente para una convergencia con los procesos corporales en juego en estos años tempranos, cruciales en la escolarización y la socialización. De hecho, no interesa si los niños(as) "entienden" o no en un sentido cognitivo lo que están haciendo. En su lugar, lo importante es la reiteración diaria corporal que acompaña las canciones, la música, los ritmos marciales, el golpe de tambores y otras actividades que tienen una poderosa resonancia emocional. Tanto respecto al argumento fenomenológico que estoy desarrollando, como al punto de vista pragmático de los(as) maestros(as), es del todo irrelevante que los(as) niños(as) no entiendan cabalmente o que no estén en capacidad de explicar, lo que indica un nivel más alto de conceptualización, las canciones. Tal como lo hicieron saber varias maestras(os), lo que cuenta no es tanto que los(as) niños(as) entiendan esos cánticos y oraciones; se trata, más bien, de que los sientan y los absorban, como todas las cosas necesarias para hacer de ellos(as) pequeños hindúes/indios. 


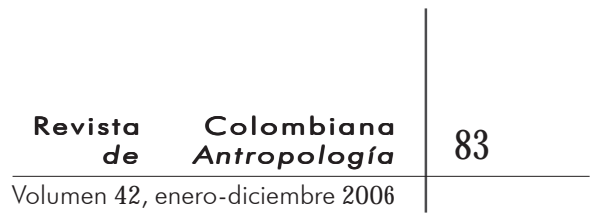

Muchos maestros revelaron que cuando tenían la edad de sus alumnos tampoco entendían el significado de las canciones ni las oraciones que solían cantar. De manera similar, algunos padres comentaron que sólo después de mucho tiempo fueron capaces de relacionar algunos de los significados de las oraciones y las canciones que debían memorizar y cantar a diario en su infancia. Pero, como añadían a menudo los profesores hindúes, el hecho de que fueran cantadas como prarthana (oraciones) era muy poderoso, ya que les daba un carácter "sagrado" (pavitra). Según ellos, esta importancia la comprendían todos los niños, ya que se asemeja a lo que harían en la alabanza divina en sus hogares. Por supuesto, esto deja fuera de consideración las implicaciones que dicha pedagogía tiene para los maestros y alumnos musulmanes en las escuelas maratíes, asunto que he tratado en otro trabajo (Benei, n. d.). Como veremos al final, esto remite, en general, a las limitaciones de la incorporación emocional de la nación.

Así, se observa de nuevo la importancia decisiva de las melodías y de la musicalidad de las canciones, que permiten la accesibilidad inmediata a los niños, y constituyen a su vez una poderosa reserva emocional. En este punto sobresale la "eficacia simbólica" de la reiteración diaria de las palabras que se emplean en la producción de la madre-India. Es más adelante en la vida, o durante la vida adulta, que el significado de lo que antes se cantaba mecánicamente se vuelve explícito. Entonces, incluso situaciones inesperadas pueden disparar algún comportamiento a manera de reacción, activando alguna asociación o representación particular; por ejemplo, cuando en los cursos de capacitación a los maestros se les solicita que retomen su experiencia infantil y canten himnos patrióticos. En estas circunstancias, a menudo durante la capacitación los adultos se veían sorpresivamente infantilizados por sus instructores; entonces, no hacían más que adoptar un patrón disciplinario internalizado desde sus días escolares; el mismo patrón que reproducen en su vida profesional con sus propios alumnos $^{19}$. Otras situaciones pueden ser más dramáticas, en especial las

19. En este caso, es probable que la adecuación tuviera que ver con que el instructor era un señor mayor de setenta años, quien confiaba plenamente en la enseñanza por medio de cuentos, canciones e historias para niños. A medida que él cantaba y contaba las historias, el lenguaje corporal de la mayoría de los(as) maestros(as) en formación era una reminiscencia del embeleso infantil: ojos deslumbrados, cuerpo tensionado, enderezamiento del cuerpo, sonrisas, asentimientos con la cabeza, eran los rasgos más comunes, entre otros. Tales momentos parecen activar algún tipo de procesos por medio de los cuales los adultos "alcanzan su niño interior" -parafraseando a Erik Erikson-y se inspiran, o retoman, las situaciones ritualizadas de su infancia. 


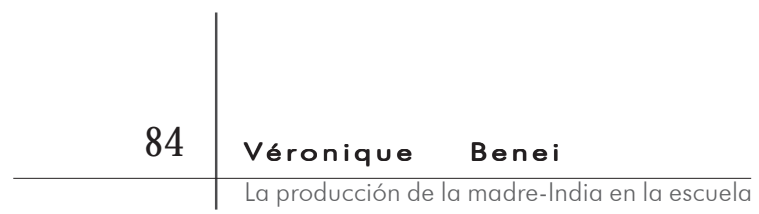

que desencadenan ansiedad sobre el cuerpo y la integridad de la madre-nación amenazada, en las se involucra una percepción de necesidad de protección. Tal es el caso del largo problema de Kashmir (Cachemira) y la (im)posibilidad visceral de los indios de aceptar la división, ya sea para permitir un estado independiente o, "peor todavía”, una fusión con Pakistán.

\section{Reproducción DE GÉNERO Y NACIÓN Y NEGOCIACIONES FEMENINAS}

A PRODUCCIÓN DE LA FIGURA DE LA “MADRE" EN LA FAMILIA, LA ESCUEla y la nación involucra, además, un poderoso registro gue- rrero, al menos en esta parte de la India. La índole guerrera se manifiesta no sólo en la conceptualización de la cualidad mitológica guerrera de la madre India: así mismo, dicha conceptualización y reproducción de la madre-nación contribuye mucho a la producción informal del género en la escuela. Durante los dos años siguientes al conflicto de Kargil (mayo-julio de 1999), esta cualidad fue desplegada de nuevo en diversas formas, con el refuerzo consecuente de las ideologías de género y guerreras incorporadas desde temprana edad. El despliegue del poder masculino, expresado mediante los actos de bravura heroica de los hijos de Bharat Mata, en especial los soldados, ocupaba el lugar más destacado. Las maestras, de manera muy visible, desempeñaron un rol activo en esta producción de género. Al enseñar la guerra a los alumnos varones, se encargaban de reproducir metáforas generizadas de la maternidad y la guerra, apelando a la imagen de la madre que se despide de sus hijos en marcha al combate por la defensa del país. Quisiera ejemplificar lo anterior tomando como caso los ensayos y preparativos del espectáculo para la "reunión anual", prevista para enero de 2000, de la sección de jardín infantil (balwadi) de la escuela primaria más progresista de la ciudad: Pratapsingh Vidhya Mandir (PVM), manejada por Antar Bharati, una sociedad educativa socialista y pro libertaria. Las profesoras, todas mujeres, prepararon con denuedo la escena, alineando a los niños para la última presentación, mientras les hacían las recomendaciones finales.

El espectáculo incluía cuatro actos representados y danzados. Los tres primeros, simples danzas circulares, incluían la danza 


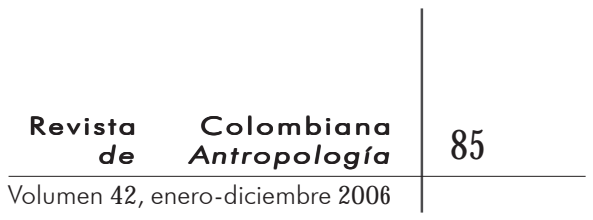

del pescador, obligatoria en todos los espectáculos escolares. No obstante, el cuarto y último acto no fue para nada ordinario. $\mathrm{O}$ al menos eso pensé ese día, poco después de mi regreso a Kolhapur. Pero como pude descubrirlo semanas después, en realidad se había incorporado a la rutina de todas las escuelas maratíes. En síntesis, el acto era una re-creación de la "guerra de Kargil”. Seis niños de entre tres y cinco años yacían sosteniendo un bastón de madera que representaba un fusil. Las maestras, empleándose en serio, enseñaban a los niños cómo representar los disparos en un combate. Algunos de los pequeños no parecían interesarse en estos procedimientos, mientras otros eran más receptivos con las lecciones marciales. Mientras esto sucedía, una niña de cuatro años danzaba tímidamente en la parte delantera del escenario, haciendo gestos de arabesco hacia el cielo, en un intento tímido aun cuando sonriente de representar su amor y fascinación por el país. El celo con que las maestras se preocupaban porque todo fuera absolutamente correcto, así como el tiempo dedicado a los ensayos, indican la importancia de este acto. Como lo expresó con vehemencia al final de uno de los ensayos Kamala B., una de las maestras: "Esto debe ser como en Kargil; como usted sabe, en Kargil hay una guerra, y ellos [señalando a los niños] deben aprender".

El despliegue de estos actos performativos subraya también la idea de la fragilidad y la dependencia que para su supervivencia tiene la nación de sus hijos varones, y la subordinación de las niñas en este proyecto nacional. En efecto, dicha producción generizada, con la incorporación de la nación en la escuela, tiene como consecuencia el desarrollo de modelos de comportamiento "propiamente femeninos", en concordancia con normas patriarcales de subordinación femenina que también valorizan el papel de la maternidad y de la madre. Estos modelos se despliegan en la vida cotidiana constantemente, una y otra vez. Aun cuando el principio de igualdad de género se expresa convenientemente de dientes para afuera en la escuela -con la enseñanza de las bases constitucionales en cuarto grado-, esta refuerza, en todos sus aspectos, el mensaje contrario: que las mujeres van de segundas. Esto lo ejemplifica una infinidad de sutilezas durante la jornada-desde la proxémica, pasando por la sexualidad y la higiene- en las que los varones tienen prioridad: como, por ejemplo, en el orden de los puestos en las clases mixtas, o cuando se trata de la salida del salón para ir a 


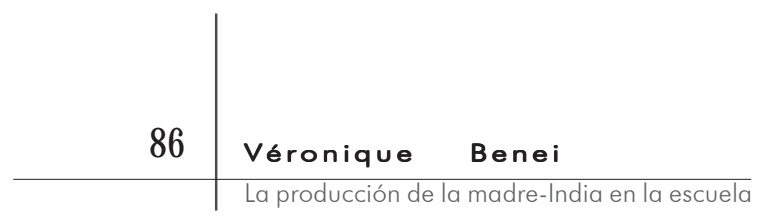

recreo, al ir al baño, al bajarse del bus en el paseo anual, al visitar un lugar público en estos paseos; o, incluso, cuando se construyen unos baños en concreto para varones, mientras las niñas deben seguir yendo a esconderse tras una reja improvisada, como sucedía todavía en la vMS en 2000.

Probablemente, una de las razones por las cuales la producción de estos patrones puede ser tan poderosa para los alumnos es porque son ejemplificados por una mayoría abrumadora de mujeres maestras, por lo que llegan a parecer los patrones legítimos. Eventualmente, la escuela es también el espacio en el que se reproducen y refuerzan estos modelos de comportamiento asociados a la amalgama de "la buena esposa, la buena madre y el buen patriotismo". Con todo, la re-presentación de esos ideales no impide la posibilidad de la inversión liberadora de roles, en la que las mujeres, en virtud de su posición como maestras, están también en posición de transmitir indirectamente mandatos a los padres varones de sus alumnos, haciendo uso de su rol como garantes del orden nacional. Por ejemplo, en una clase de tercer grado de lengua maratí en el PVM -niños mayores de ocho años-, en octubre de 1999, el asunto de la invención y la introducción de la televisión en la India llevó de repente a una charla magistral sobre cívica y patriotismo. La profesora, Sherifabai, musulmana aguda y vivaz al filo de sus cuarenta años, invitó a sus alumnos al terminar la clase para que limitaran su consumo diario de televisión, y les dijeran a sus padres que vieran las emisiones diarias de noticias. Mientras ella se quejaba de que los padres suelen apagar la televisión tan pronto se termina la película, justo antes del inicio de las noticias, un niño exclamó: “iComo hace mi papá!”. A lo que Sherifabai respondió: "Bien, de ahora en adelante debes decirle a tu papá que vea las noticias... Sí, como lo oyen, deben decir a sus papás que vean las noticias para que así todos sepan mejor lo que está pasando en el país, lo que está pasando en nuestro país (apla desh), y lo que está pasando en otros países”. Luego de una pausa, retomó su charla con más vehemencia, haciendo referencia a los militares (sainik) en Kargil: "Mientras nosotros estamos sentados en nuestras casas viendo la televisión, ellos están combatiendo por nuestro país, están dando sus vidas por nosotros. Por tanto, debemos ver las noticias".

Más aún. El análisis de las instancias de producción de los modelos dominantes de rol, a los que se espera se amolden las profesoras en el contexto de la escuela, lleva a preguntarse sobre 


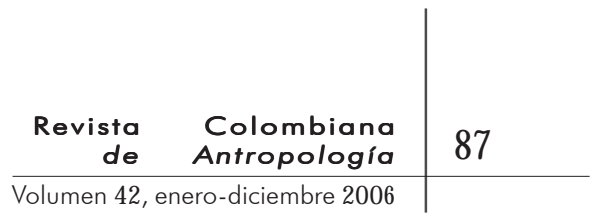

los márgenes y la libertad de acción que obtienen para sí mismas las mujeres en un proceso de negociación, así como a cuestionar los procesos y las instancias mismas. Si las instituciones sociales son espacios de género y de producción de roles de género, este último proceso no debe ser malinterpretado como definitivo y absoluto, como si fuera hegemónico, al punto de descartar por adelantado cualquier modelo alternativo. En gran medida, en la actualidad las comprensiones dicotómicas de las categorías de lo masculino y lo femenino en la sociedad de la India, como en muchas otras sociedades, son el resultado de negociaciones coloniales con ideas victorianas (Herdt, 1982; Connell, 1995). Siendo el resultado de negociaciones, en la actualidad las posibilidades para pensar el género en la India no se han agotado, pero tampoco se deben menospreciar las contingencias. Lo mismo puede decirse en relación con la supuesta homogeneidad de las realidades que giran en torno a las categorías de lo masculino y lo femenino en el psicoanálisis. Como lo ilustró hace unos años Nancy Chodorow, las categorías empleadas en el discurso psicoanalítico, sin exclusión del discurso freudiano y el lacaniano, han operado ampliamente en el marco de unas formaciones normativas que ligan la heterosexualidad a la dominación masculina y la sexualidad al género (véase Chodorow, 1994). Chodorow llama la atención sobre la presuposición implícita de modelos homogéneos de feminidad y masculinidad, que de manera engañosa restablecen ideas de normalidad y desviación. Mas, si cabe, estas categorías son arbitrarias y relativas (Foucault, 1973). Esta precaución es necesaria para abordar la producción generizada de conocimientos, cuerpos, sujetos disciplinados, ciudadanos e instituciones, junto con normas y valores. Al igual que la socialización temprana, estos procesos implican sistematización. En otras palabras, la construcción generizada de ciudadanos y naciones, aun cuando acuda a procesos de incorporación y al despliegue sucesivo de sensoriums constituidos de maneras diversas, siempre es incompleta. Se necesita un trabajo cotidiano para perpetuar las apariencias de disposiciones basadas en habitus. Pero incluso el habitus admite fallas e intersticios, desde donde los actores sociales -ya sea miembros de la familia, niños(as) o maestros(as), en tanto que desarrollan su yo socialmente interiorizado- pueden desarrollar "arts de faire" apelando a mecanismos de adaptación y a astutas negociaciones. En consecuencia, bien sea en el campo de la salud y la higiene o en el de la educación, las instituciones con las que 


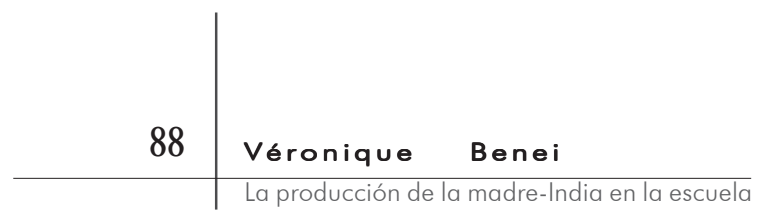

cuenta el estado no pueden imponer su voluntad sobre los agentes sociales. En cambio, las instituciones están compuestas de y por actores sociales en una sucesión de procesos de ajuste (Fuller y Benei, 2000). Como muestro en otro trabajo, en relación con el nuevo programa de educación ética introducido por la coalición de extrema-derecha hindú en el poder entre 1995y 1998 en el estado de Maharashtra (Benei, 2000), incluso los maestros negocian las instrucciones estatales en su trabajo diario.

¿De qué manera las "mujeres" como actores sociales acomodan las restricciones sociales que les son impuestas, y cuáles son los intersticios en el tejido social en los que pueden tejer su propia negociación? ¿De qué recursos disponen fuera del marco tradicional de la vida rural y las canciones populares en el marco del recinto escolar? (Bagwe, 1995, Grodzins Gold y Raheja, 1994; Raheja, 2003). Las posibles formas de negociación varían desde la pura diplomacia hasta la resistencia abierta. A pesar de haber estado sometidas a una fuerte presión por adaptarse a las expectativas patriarcales dominantes de una maternidad pedagógica y patriótica, a menudo las maestras recurren a la diplomacia. Activa y sutilmente, están comprometidas con el patrón común de dominación de género que prevalece en la sociedad de la India en general, aun cuando parecen bastante sumisas e instrumentales en su fomento. Uno de los ejemplos más dicientes de esta realidad es el código del vestuario.

Ya hemos visto cómo, en esta parte de Maharashtra, en el código del vestido el "sari moderno" es privativo de las mujeres casadas. La mayor parte de las maestras se conforma con este código en el trabajo de manera más bien franca, e incluso algunas veces, con expresiones de orgullo. Así, en todas las escuelas maratíes en las que hice el trabajo de campo, incluso en las más progresistas, escuché a menudo comentarios como el siguiente de parte del personal femenino: "Es parte de nuestra cultura maharashtriana, de nuestra cultura India: después del matrimonio las mujeres no deben usar nada distinto del sari" (amci Maharashtratli sanskruti ahe, amci Bhartiya sanskruti, lagna jhale ki striyala saric nesayci). Así mismo, las maestras estigmatizaban rápido y en público cualquier "desviación” en el vestido, ya se tratara de sus colegas o de cualquier otra mujer, incluyendo las extranjeras -como la antropóloga-. Dichas formas "desviadas" del vestido incluían los trajes al estilo Punjabi -usados también por la antropóloga-, a la moda en Maharashtra, no sólo entre las 


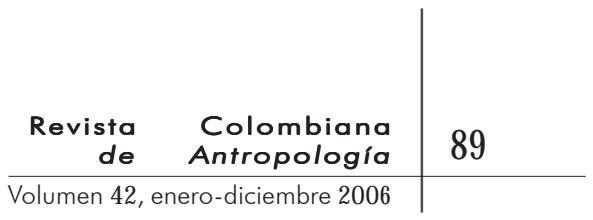

jóvenes solteras, sino también entre las clases altas urbanas, orgullosas de darse un toque de "modernismo" y "cosmopolitismo”. Sin embargo, conocí dos casos en los que la estricta norma del sari se rompió, sin que como consecuencia hubiera sanción. La maestra de arte, Kavita R. y Pushpa S., una de las maestras regulares -de un total de dieciséis mujeres que conformaban el equipo de trabajo-, ambas jóvenes y solteras, usaban de manera regular vestidos Punjabi en la escuela PVM (véase más arriba). Aun cuando a veces eran objeto de bromas por parte de algunos colegas mayores, nunca fueron particularmente segregadas del resto de la comunidad educativa, ni alguno de los consecutivos directores de la escuela les exigió cambiar sus hábitos. Al menos en el caso de Pushpa, era evidente que su rechazo del código del vestido esperado era una manifestación de su resistencia a las presiones familiares y de sus pares, y constituía una declaración abierta de autonomía e independencia frente a los modelos patriarcales de feminidad. Más aún, ella nunca usaba joyas, y ni siquiera un ligero toque de maquillaje, a diferencia de la mayoría de las colegas de su edad; incluso, en varias ocasiones habló de manera incidental del poco entusiasmo que le producía el matrimonio.

Que la posición de Pushpa ocupe uno de los extremos de un continuum de negociaciones posibles es indicativo de un punto más general: que los patrones de comportamiento cultural y socialmente sancionados con los que se espera que las mujeres se conformen públicamente, en particular en su trabajo como profesoras, no abarcan toda la acción social, ni adentro ni afuera de la escuela. Con seguridad, el énfasis discursivo en la "cultura maharashtriana" (maharashtratli sanskruti), en "las costumbres de la India" (bhartiya paddhati) y en otros asuntos por el estilo, desplegados por las mujeres en el transcurso de conversaciones públicas, puede hacer aparecer una visión de extrema rigidez en el seguimiento de los patrones de comportamiento por fuera de los espacios públicos. Sin embargo, esta visión contrasta fuertemente con el comportamiento de la mayoría de los profesores afuera de sus entornos profesionales, como pude observar luego de mi investigación. Cuando pude visitar a los maestros en sus hogares encontré que incluso entre los defensores acérrimos del patriarcado el comportamiento en la casa era mucho más relajado que en la escuela, ya sea en el salón de clases o fuera de él. En numerosos casos, los maestros se portaban en sus casas de una manera muy distante de las normas que seguían en la escuela. Es 


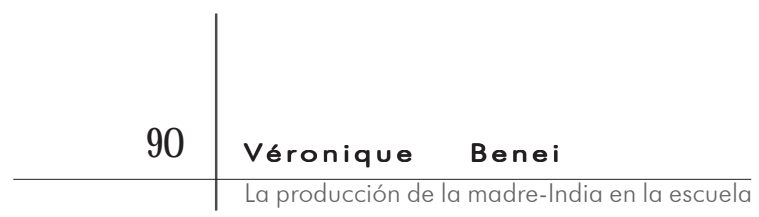

el caso de una de las profesoras de alto rango, perteneciente a la antigua guardia hindú, Ms. Pratima Bhaviskar, de la vMS, quien a menudo hacía pronunciamientos públicos sobre la "tradición maharashtriana” y a obligaciones de las mujeres casadas, como portar el sari, llevar el pelo bien cogido y abstenerse de maquillarse. Ya me había invitado varias veces, cuando finalmente pude visitarla en las fiestas de Diwali en 2000. El día que fui, en octubre, me presentó a sus dos hijas: ambas casadas, pasaban la mayor parte del día en su hogar materno mientras sus esposos trabajaban. Una de ellas administraba un pequeño salón de belleza en la casa, y estaba muy maquillada. Ambas hermanas usaban vestidos Punjabi dentro y fuera de la casa y llevaban su pelo suelto, como lo harían las "cosmopolitas" señoras de la clase media alta maharashtriana. Cuando amablemente le mencioné esto, Pratima Bai me respondió con una sonrisa un poco avergonzada que "hoy en día es la moda llevar el pelo suelto, y usar vestidos Punjabi; no es un problema”. Incluso trató de persuadirme de que aun cuando el sari y el cabello recogido fueran obligatorios en el colegio, yo, también, podría permitirme soltarme el cabello cuando estuviera en el colegio. Este no es sino uno de muchos ejemplos posibles, mediante el cual se muestra cómo las mujeres más asertivas en la observancia de las normas culturales y de las reglas del colegio, una vez fuera de las celosas miradas del entorno profesional podían ser encontradas usando un Punjabi, no solo en casa, sino también en las salidas familiares. En muchas ocasiones, reconocían en privado preferir, por sobre el sari, una prenda más confortable y descomplicada como el Punjabi. El código del vestido puede encontrarse entre las instancias más triviales y recurrentes de negociación; aunque había muchas otras, incluyendo eventos relacionados con los ciclos vitales, como matrimonios, en los que los preparativos escapaban del ámbito de las posibilidades más comunes y aceptables. En todos los casos, dichas instancias de negociación confirman la importancia fundamental de situar el ámbito escolar en un contexto cultural y social más amplio, así como de desenmarañar los hilos múltiples, variados y coloridos de la vida personal de las maestras fuera del contexto laboral. 


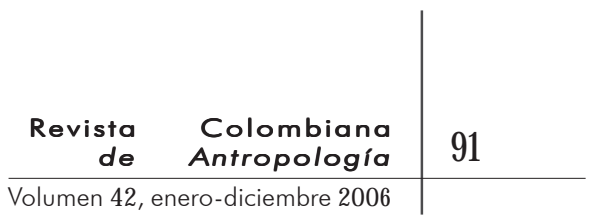

\section{Conclusión}

STE RELATO DE LA PRODUCCIÓN GENERIZADA DE LA NACIÓN POR MEDIO

- de un continuum que pasa por la familia, la escuela y la

L nación, subraya la necesidad de reconsiderar la dicotomía público/privado de dos modos. Primero, en la producción de cualquier tipo de espacio se debe tener en cuenta la dimensión constitutiva del género como producción discursiva y material. En efecto, la constitución de esos espacios sociales y culturales es trabajada por nociones y prácticas locales de género que se pueden fortalecer en el proceso, pero cuya normativa nunca puede agotar el ámbito de sus negociaciones por actores sociales. Segundo, documentar la producción del género y de la nación junto a la de varios espacios en los que se constituyen instituciones y personas provee un modo alternativo para pensar más sobre sus respectivos entendimientos dicotómicos. Si en principio las categorías de lo "público" y lo "privado" fueron adecuadas para pensar y, en especial, para describir la configuración de un espacio nacional, del espacio de los medios de comunicación y los procesos concomitantes del siglo diecinueve, en la actualidad muy a menudo estas categorías se asumen como modelos empíricos.

Richard Sennett sostenía hace años en un libro muy aclamado (1974), que recurrimos a la esfera íntima por temor a una realidad incierta. Estamos permeados por el narcisismo, no en forma de amor propio, sino en términos de una referencia exclusiva a nosotros mismos. Ante la ocurrencia de cualquier evento, nos preguntamos por el sentido que tiene para nosotros. Así, el sujeto narcisista busca experiencias "reales" e intensas sólo en el marco de sus propias necesidades y expectativas. Sennett sostenía que los orígenes del yo narcisista y de la "sociedad íntima" -en la que las relaciones sociales son tratadas como pretextos para la expresión de la personalidad-se fundan en la erosión de una vida pública impersonal en la Europa del siglo diecinueve. Desde entonces, algunos autores han declarado que, a pesar de haber sido hecho en 1970, el análisis de Sennett resuena con mayor vigor en nuestro momento histórico, caracterizado por un proceso de personalización que involucra una intensa inversión en la vida privada y la reducción de la esfera pública. Suele decirse que en la actualidad toda la esfera pública está inundada de formas de "intimidad pública": desde los talk-shows a 


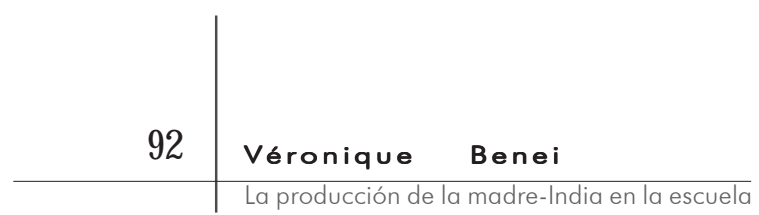

modo de confesionarios, hasta los reality-shows, pasando por la vida privada de los líderes políticos.

Sin embargo, en este artículo he tratado de demostrar que existe otra forma de considerar las categorías de lo "público" y lo "privado", que devuelve su historicidad a dichas herramientas analíticas fundamentales que emergen en un contexto histórico determinado, y, en esa medida, las deja en paz. Este acercamiento pasa por reconocer, primero, hasta qué punto dichas categorías han adquirido un valor atemporal, como si se tratara de una realidad concreta, reificada, que funcionara como la "cristalización de un modelo adaptable a toda circunstancia” (Arfuch, 2002: 75). Además, como espero haberlo demostrado, la noción de sensorium desarrollada aquí ayuda a reconsiderar el supuesto "antagonismo entre la esfera íntima y la esfera pública/social [que] no es sino un efecto del discurso: reglas, coacciones, dispositivos de poder, impulsos y emociones", como sostiene Arfuch (Ibídem: 74).

En efecto, el caso de la educación escolar en la India sugiere una especificidad en las maneras en que se articula la producción del sentimiento nacional/regional con un sentimiento notablemente generizado de parentesco ficticio, mediante la noción de madre en particular. En su investigación sobre Egipto, Lila Abu-Lughod (1986) sostiene que las escuelas "privatizan" al individuo y a la familia beduinos, corroyendo las identidades con los grupos de parentesco, una de las bases de resistencia frente al estado. En contraste, en las escuelas maratíes de la India la figura misma de la familia, y en particular la de la madre, emerge como mediación entre la familia, la escuela y la nación. Esta mediación, que se inicia en el jardín infantil y se prolonga más adelante, facilita la producción de un sensorium en el que se imbrican las experiencias de la infancia temprana con las de la escuela, lo que sirve a su vez a la producción escolar de sujetos nacionales y regionales. De esta manera, como sucede en Japón, la performancia nacional (y regional) del canto recupera e invoca activamente "la relación más íntima, físicamente hablando, aquella de la madre y su hijo", en un intento por "establecer un vínculo sensual entre todos los ciudadanos de la nación como hijos" no solo de sus propias madres, sino, de forma igualmente decisiva, de la "madre nación” (Yano, 1995 458-459).

A diferencia de Japón, sin embargo, la producción de este vínculo sensual en el caso maharashtriano es doble: la nación 


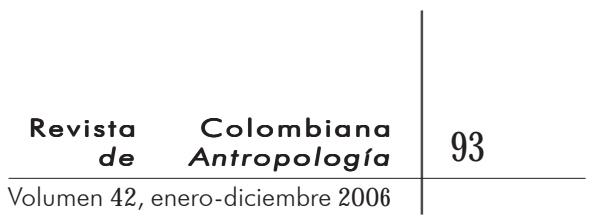

necesita ser concebida como madre para producir dicha conexión entre todos los ciudadanos. Además, la lengua materna (matru bhasha) selecciona los habitantes del estado regional, marcando los que se consideran parte de la comunidad maharashtriana y están asociados con una herencia regional. Mediante el tropo de la madre, se crea entonces una definición emocional de la identidad nacional y regional, junto con los lazos de anhelo. Esta noción es importante y puede aplicarse a muchos casos de nacionalismo.

Más aún. En su trabajo sobre las relaciones de la televisión en la India con el nacionalismo hindú, Arvind Rajagopal (2001) hizo su análisis a partir de esta noción de anhelo: la emisión del seriado nacional de la épica hindú, Ramayana, cristalizaba el deseo y el anhelo por una nación auténtica inmersa en una era de oro. Si articulamos los argumentos de Rajagopal con la noción psicoanalítica de deseo de Kakar, centrada de manera primaria en la madre -una noción derivada del concepto, en principio desarrollado por Melanie Klein, de apego primario hacia la madre como fuente de gratificación y deseo- podemos decir que la escuela funciona como la matriz de la nación en la que se reproduce a diario la diosa de la India, se producen sus hijos, sus futuros patriotas anhelantes. Así se vuelve claro cómo quienes no hablan maratí o no son hindús no pueden ser concebidos como integrables en el redil nacional/regional, sin importar todas las manifestaciones que de dientes para afuera expresen la tolerancia religiosa y la integración nacional. Incluso, las profesoras que menos simpatizan con la línea hindutva, implícitamente articulan en términos hindúes sus explicaciones relacionadas con las conceptualizaciones de la madre-diosa-nación. En raras ocasiones, los maestros hindúes -brahmines, maratha o de castas inferiores- manifestaron algún sentido de conciencia inclusiva frente a sus alumnos no hindúes. Ello no quiere decir que el punto de vista sobre la ciudadanía de los maestros más progresistas se limitara a las visiones que al respecto impulsaban la coalición de extrema-derecha hinduista Shiv Sena, BJP o la RSS. En el caso de algunos profesores caracterizados por su ecuanimidad, ello se debía más bien al carácter dominante de la cultura hindú a través de la India como fuente primaria para la definición de la cultura nacional. Es tal el poder de la experiencia fenomenológica escolar que asienta sus premisas primarias en nociones hindúes, que ellas pasan inadverti- 


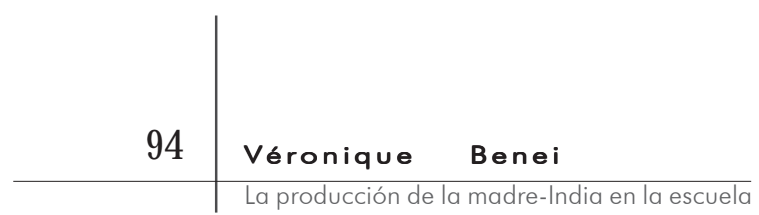

das, o, más bien, que sus implicaciones políticas no salen a flote.

Por fin, las tiranías y servidumbres de los mundos público y privado a los que se refería la escritora inglesa feminista Virginia Wolf, y que también invierten consideraciones centrales de género, no aparecen tan distintos como el producto de una distinción arbitraria que se disuelve en el mundo de la vida cotidiana en nuestra época. Más aún, Arfuch agrega que las transformaciones políticas de las últimas décadas, así como el despliegue incesante de nuevas tecnologías, han acabado con el significado clásico de lo público y lo privado, al punto de tornar su distinción tenue e "inefable" (Arfuch, 2002: 76). Quisiera sugerir que ello no sólo es cierto a la luz de dichas transformaciones, sino, tal vez de manera fundamental, a la luz de los procesos de construcción del yo que han venido ocurriendo con la generalización de la escolarización, en especial en esta parte de la India donde más de $75 \%$ de la población está alfabetizada.

\section{Bibliografía}

Abu-Lughod, Lila. 1986. Veiled sentiments: Honor and poetry in a Bedouin society. University of California Press. Berkeley.

Anzieu, Didier. 1985 Le moi-peau. Dunod. París. The Skin Ego. 1989. Yale University Press. New Haven y Londres. (El yo piel. 1987. Biblioteca Nueva. Madrid).

ARFuCh, LeONOR. 2002. El espacio biográfico. Dilemas de la subjetividad contemporánea. Fondo de Cultura Económica. Buenos Aires.

Assayag, Jackie. 2003 Désir de nation. Odile Jacob. París.

Bagwe, Anjali. 1995 Of woman caste: The experience of gender in rural India. Zed Books. Londres.

Banerjee, Mukulika y Daniel Miller. 2003 The sari. Berg. Oxford.

Benei, Véronique. 2000. "Teaching nationalism in Maharashtrian schools". En C. J. Fuller y V. Benei (eds.). The everyday state and society in modern India. Social Science Press. Delhi.

.n. d. "Nationalizing children: An ethnography of schooling, gender and violence in western India". Manuscrito.

BEREZIN, Mabel. 1997. Making the fascist self. The political culture of interwar Italy. Cornell University Press. Ithaca. 


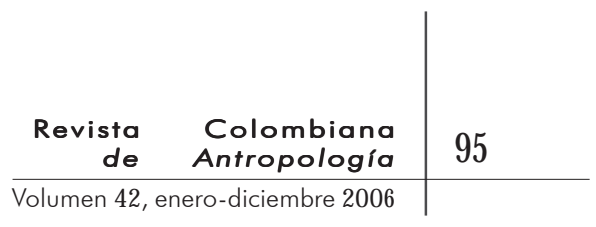

Calhoun, Craig. 1997 (1992). "Introduction: Habermas and the public sphere”. En Craig Calhoun (ed.). Habermas and the public sphere. MIT Press. Cambridge.

ChatterJee, Partha. 1993 The nation and its fragments: Colonial and postcolonial histories. Princeton University Press. Princeton.

Chodorow, Nancy. 1994. Femininities, masculinities, sexualities: Freud and beyond. Free Association Books. Londres.

CONNeld, RoBert W. 1995 Masculinities. Polity. Cambridge. (Masculinidades. 2003 PUEG-Unam. México).

Epstein, D. y R. Johnson. 1998. Schooling sexualities. Open University Press. Buckingham.

ERIKSON, ERIK H. 1963 Childhood and society. Norton. Nueva York. Segunda edición. [Infancia y sociedad. 1950. Editorial Paidós. Buenos Aires].

—. 2002 (1979). "Introductory lecture”. En Sudhir Kakar (ed.). Identity and adulthood. Oxford University Press. Delhi.

Foucault, Michel. 1981 The history of sexuality: Vol. 1 An introduction. Harmondsworth. Londres. (Histoire de la sexualité. Vol. 1 La volonté de savoir. 1976. Gallimard. París). (Historia de la sexualidad. Vol. 1 La voluntad del saber. 1991 Siglo XXI. Bogotá).

1979. Discipline and punish. Harmondsworth. Londres. (Surveiller et punir. 1975 Gallimard. París). (Vigilar y castigar. Nacimiento de la prisión. 1990. Siglo XXI. México. 18a edición).

FuLLER, C. J. y VÉRONIQUE BENEI (eds.). 2000. The everyday state and society in modern India. Social Science Press/Londres, Hurst \& Co./Delhi,

Gilligan, Carol. 1982. In a different voice: Psychological theory and women's development. Harvard University Press. Cambridge. (La moral y la teoría: psicología del desarrollo femenino. 1985 Fondo de Cultura Económica. México).

Goswami, Manu. 2004. Producing India. From colonial economy to national space. University of Chicago Press. Chicago.

Grodzins Gold, Ann y Gloria Goodwin Raheja. 1994. Listen to the heron's words: Reimagining gender and kinship in North India. University of California Press. Berkeley.

Gupta, Charu. 2001 Sexuality, obscenity, community: Women, muslims and the Hindu public in colonial India. Permanent Black. Delhi.

HARLEKAR, H. 1983 Martahi gane. Kolhapur.

Herdt, Gilbert H. (ed.). 1982. Rituals of manhood: Male initiation in Papua New Guinea. University of California Press. Berkeley.

Janov, Arthur. 1970. The primal scream. Putnam. Nueva York. (El grito primal. Terapia primal: la curación de la neurosis. 1975 Suramericana. Buenos Aires. Segunda edición). 


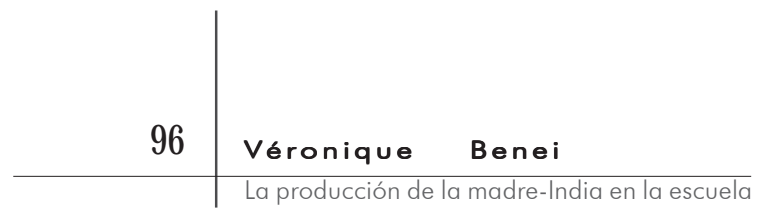

KAKAR, SudHIR. 1999 (1978). The inner world. A psycho-analytic study of childhood and society in India. Oxford University Press. Delhi.

KAVIRAJ, Sudipta. 2001 “In search of civil society”. En Sudipta Kaviraj y Sunil Khilnani (eds.). Civil society. History and possibilities. Cambridge University Press. Cambridge.

Klein, Melanie. 1964. "Love, guilt and reparation”. En Joan Riviere y Melanie Klein (eds.). Love, hate and reparation. W. W. Norton \& Co. Nueva York. (Amor, odio y reparación: emociones básicas del hombre. 1981 Hormé. Buenos Aires. Cuarta edición).

Koonz, Claudia. 1987. Mothers in the fatherland: Women, the family, and Nazi politics. St. Martin's Press. Nueva York.

Kumar, Krishna. 2001 Prejudice and pride. School histories of the freedom struggle in India and Pakistan. Viking. Delhi.

Kumar, Nita. 2000. Lessons from schools. The history of education in Banaras. Sage. Delhi.

KumAR, RADHA. 1993 The history of doing: An illustrated account of movements for women's rights and feminism in India, 1800-1990. Verso. Londres.

LyOtARD, JEAN-FranÇOIS. 1993 (1982). "Answering the question: What is postmodernism?”. En Thomas Docherty (ed.). Postmodernism: A reader. Harvester Wheatsheaf. Nueva York.

1984. The postmodern condition: A report on knowledge (translation from the French by Geoff Bennington and Brian Massumi, orig. 1979). University of Minnesota Press. Minneapolis (La condición posmoderna: informe sobre el saber. 2004. Cátedra. Madrid).

Parry, Jonathan, 1994. Death in Banaras. Cambridge University Press. Cambridge/Nueva York.

Raheja, Gloria Goodwin (ed.). 2003 Songs, stories, lives: Gendered dialogues and cultural critique. Kali for Women. Delhi.

Rajagopal, Arvind. 2001 Politics after television: Religious nationalism and the reshaping of the Indian public. Cambridge University Press. Cambridge/Nueva York.

Ramaswamy, Sumathi. 1998. "Body language: The somatics of nationalism in Tamil India”. Gender and History. 10 (1).

Rank, Отто, 1957 (1952). The trauma of birth. Brunner. Nueva York. (EI trauma del nacimiento. 1975 Paidós. Buenos Aires).

Sarkar, Tanika. 2001/2002. Hindu wife, Hindu nation: Community, religion and cultural nationalism. Permanent Black/Indiana University Press. Nueva Delhi/Bloomington. 
SENNETT, RICHARD. 1974. The fall of public man: On the social psychology of capitalism. Vintage Books. Nueva York (El declive del hombre público. 1978. Península. Barcelona).

Trawick, Margaret. 1989. Notes on love in a Tamil family. University of California Press. Berkeley.

WOODWARD, RACHEL. 2002. "Locating military masculinities: The role of space and place in the formation of gender identities in the Armed Forces". En Paul R. Higate (ed.). Military masculinities: Identity and the state. Greenwood Press. Londres.

YANo, Christine R. 1995 "Shaping tears of a nation: An ethnography of emotion in Japanese popular song". PhD tesis. University of Hawaii. 